\title{
14,15-Epoxyeicosatrienoic Acid Alleviates Pathology in a Mouse Model of Alzheimer's Disease
}

\author{
Wenjun Chen, ${ }^{1,2^{*}}$ Mengyao Wang, ${ }^{1,2^{\star}}$ Minzhen Zhu, ${ }^{1,2}$ Wenchao Xiong, ${ }^{1,2}$ Xihe Qin, ${ }^{3}$ and Xinhong Zhu ${ }^{1,2,4,5}$ \\ ${ }^{1}$ Institute of Mental Health, School of Basic Medical Sciences, Southern Medical University, Guangzhou 510515, People's Republic of China, ${ }^{2}$ Key \\ Laboratory of Mental Health of the Ministry of Education and Guangdong Province Key Laboratory of Psychiatric Disorders, Guangzhou 510515, \\ People's Republic of China, ${ }^{3}$ Eusyn Medical Technology Company, Guangzhou 510663, People’s Republic of China, ${ }^{4}$ School of Psychology, Shenzhen \\ University, Shenzhen 518060, People's Republic of China, and ${ }^{5}$ Guangdong-Hong Kong-Macao Greater Bay Area Center for Brain Science and \\ Brain-Inspired Intelligence, Guangzhou 510515, People's Republic of China
}

\begin{abstract}
Alzheimer's disease (AD) is the leading cause of late-onset dementia, and there exists an unmet medical need for effective treatments for $\mathrm{AD}$. The accumulation of neurotoxic amyloid- $\boldsymbol{\beta}(\mathrm{A} \boldsymbol{\beta})$ plaques contributes to the pathophysiology of $\mathrm{AD}$. EPHX2 encoding soluble epoxide hydrolase (sEH) - a key enzyme for epoxyeicosatrienoic acid (EET) signaling that is mainly expressed in lysosomes of astrocytes in the adult brain-is cosited at a locus associated with AD, but it is unclear whether and how it contributes to the pathophysiology of AD. In this report, we show that the pharmacologic inhibition of sEH with 1-trifluoromethoxyphenyl- 3-(1-propionylpiperidin-4-yl) urea (TPPU) or the genetic deletion of Ephx2 reduces A $\beta$ deposition in the brains of both male and female familial Alzheimer's disease ( $5 \times$ FAD) model mice. The inhibition of sEH with TPPU or the genetic deletion of Ephx2 alleviated cognitive deficits and prevented astrocyte reactivation in the brains of 6-monthold male $5 \times$ FAD mice. 14,15-EET levels in the brains of these mice were also increased by sEH inhibition. In cultured adult astrocytes treated with TPPU or 14,15-EET, astrocyte A $\beta$ clearance was increased through enhanced lysosomal biogenesis. Infusion of 14,15 -EET into the hippocampus of $5 \times$ FAD mice prevented the aggregation of $\mathrm{A} \beta$. Notably, a higher concentration of 14,15-EET $(200 \mathrm{ng} / \mathrm{ml})$ infusion into the hippocampus reversed A $\beta$ deposition in the brains of 6-month-old male $5 \times$ FAD mice. These results indicate that EET signaling, especially 14,15-EET, plays a key role in the pathophysiology of AD, and that targeting this pathway is a potential therapeutic strategy for the treatment of AD.
\end{abstract}

Key words: 14,15-epoxyeicosatrienoic acid; Alzheimer's disease; astrocyte; lysosomal biogenesis; soluble epoxide hydrolase

Significance Statement

There are limited treatment options for Alzheimer's disease (AD). EPHX2 encoding soluble epoxide hydrolase (sEH) is located at a locus that is linked to late-onset $\mathrm{AD}$, but its contribution to the pathophysiology of $\mathrm{AD}$ is unclear. Here, we demonstrate that $s E H$ inhibition or Eph $x 2$ deletion alleviates pathology in familial Alzheimer's disease $(5 \times F A D)$ mice. Inhibiting sEH or increasing 14,15-epoxyeicosatrienoic acid (EET) enhanced lysosomal biogenesis and amyloid- $\beta$ (A $\beta$ ) clearance in cultured adult astrocytes. Moreover, the infusion of 14,15 -EET into the hippocampus of $5 \times$ FAD mice not only prevented the aggregation of $\mathrm{A} \beta$, but also reversed the deposition of $\mathrm{A} \beta$. Thus, 14,15-EET plays a key role in the pathophysiology of $\mathrm{AD}$ and therapeutic strategies that target this pathway may be an effective treatment.

Received May 19, 2020; revised Sep. 16, 2020; accepted Sep. 17, 2020.

Author contributions: X.Z. designed research; W.C., M.W., M.Z., W.X., and X.Q. performed research; W.C., M.W., and X.Z. analyzed data; X.Z. wrote the paper.

*W.C. and M.W. contributed equally to this work.

The authors declare no competing financial interests.

This work was supported by the National Natural Science Foundation of China (Grant 81930034 to X.Z.), the Natural Science Foundation of Guangdong Province (Grant 2016A030308005 to X.Z.), the Guangzhou Science and Technology Project (Grant 201804020061 to X.Z.), and Key-Area Research and Development Program of Guangdong Province (Grant 2018B030334001 to X.Z.). We thank Dr. Haoxing Xu, Department of Molecular, Cellular, and Developmental Biology, University of Michigan, for gifting ML-SI3. We also thank Ying-Ying Fang, Shu-Ji Li, Ting Guo, and Xiao-Wen Li for technical support.

Correspondence should be addressed to Xinhong Zhu at zhuxh527@126.com.

https://doi.org/10.1523/JNEUROSCI.1246-20.2020

Copyright $\odot 2020$ the authors

\section{Introduction}

Alzheimer's disease (AD), the leading cause of late-onset dementia, is characterized by progressive memory decline and cognitive dysfunction, which are thought to be caused by the abnormal metabolism of amyloid- $\beta(\mathrm{A} \beta)$ that is derived from amyloid precursor protein (APP) through endoproteolytic cleavage (Selkoe, 2019). The amyloid cascade hypothesis of AD is supported by the efficacy of the anti-A $\beta$ antibody aducanumab in reducing $\mathrm{A} \beta$ plaque formation, as demonstrated in a phase 3 clinical trial (Tolar et al., 2019; Schneider, 2020). The pathologic processes induced by $\mathrm{A} \beta$ deposition begin years before $\mathrm{AD}$ is 
clinically diagnosed, suggesting that restoring normal $\mathrm{A} \beta$ processing before the appearance of symptoms could prevent or delay the onset of $\mathrm{AD}$ (McDade and Bateman, 2017).

Astrocytes have a role in most aspects of brain function, including synaptic plasticity, lipid metabolism, and neurovascular coupling, all of which may be perturbed in AD. Indeed, astrocytes have been shown to play a critical role in the cellular phase of $\mathrm{AD}$ (De Strooper and Karran, 2016). A $\beta$ peptide is preferentially internalized by astrocytes and degraded in the lysosome (De Strooper and Karran, 2016). One of the earliest events in the pathogenesis of $\mathrm{AD}$ is reactive astrogliosis adjacent to $\mathrm{A} \beta$ deposits (Koistinaho et al., 2004); thus, therapeutic strategies that restore normal $\mathrm{A} \beta$ processing by astrocytes can potentially prevent the development or progression of $\mathrm{AD}$.

Genetic studies have identified a $15.1 \mathrm{Mb}$ (megabase) region on chromosome 8p, the PTK2B-CLU locus (DeMattos et al., 2004; Butler et al., 2009; Lambert et al., 2013), that is linked to late-onset $\mathrm{AD}$. Although three of the four genes at this locus (PTK2B, CHRNA2, and CLU, which encode protein tyrosine kinase, cholinergic receptor nicotinic $\alpha 2$ subunit, and clusterin, respectively) are thought to be associated with $\mathrm{AD}$ (Matsubara et al., 1996; DeMattos et al., 2004; Butler et al., 2009; Lambert et al., 2013; Karch and Goate, 2015; Giralt et al., 2018; Polis and GilHenn, 2019), it remains unclear whether and how EPHX2, which encodes soluble epoxide hydrolase (sEH), contributes to the pathophysiology of AD. sEH is a key enzyme in the metabolism of eicosanoids, which include epoxyeicosatrienoic acids (EETs). EETs are derived from arachidonic acid (ARA) and related polyunsaturated fatty acids through the metabolism of epoxygenase (Kodani and Hammock, 2015). The brain is highly enriched in ARA, and essential fatty acids as well as their metabolites have been implicated in the pathogenesis of AD (Sanchez-Mejia et al., 2008). EETs have vasodilatory and anti-inflammatory actions, and pathophysiologic features of AD include early vascular damage and progressive inflammation (De Strooper and Karran, 2016; Wu et al., 2017). We recently reported that, in the brain, $\mathrm{sEH}$ is mainly localized in the lysosomes of astrocytes and plays an important role in regulating astrocyte function (Qin et al., 2019; Xiong et al., 2019). In the present study, we tested the hypothesis that $\mathrm{sEH}$ contributes to the pathophysiology of $\mathrm{AD}$ through the modulation of $\mathrm{A} \beta$ metabolism in astrocytes.

\section{Materials and Methods}

Mice. Mice were housed under standard environmental conditions (12 $\mathrm{h}$ light/dark cycle; temperature, $24 \pm 1^{\circ} \mathrm{C}$; relative humidity, $55 \pm 5 \%$ ) with free access to food and water. All of the experiments were conducted in accordance with the Chinese Council on Animal Care Guidelines. The mice were handled twice daily for 3-4 d before the double-blind behavioral experiments took place, which were performed between 1:00 P.M. and 4:00 P.M. All mice had the C57BL/6J background.

$5 \times$ FAD transgenic mice (catalog \#008730) and B6.129X-Ephx2tm1Gonz/J (Eph $x 2^{-l-}$ ) mice (catalog \#004165) were obtained from The Jackson Laboratory. The $5 \times \mathrm{FAD} ; E p h \times 2^{-1-}$ mice were bred by crossing $5 \times \mathrm{FAD}$ mice with Eph $x 2^{-1-}$ mice. Sex-matched littermates were used as controls. All mice were bred using in-crossed $5 \times \mathrm{FAD}$; Eph $x 2^{+/-}$mice, and only $5 \times \mathrm{FAD}$ heterozygotes were used in the present study.

The Cre-dependent ROSA26 tdTomato reporter (catalog \# 007909) mouse line was purchased from The Jackson Laboratory. The Ephx2$C r e E R^{\mathrm{T} 2}$ mouse line was generated by Shanghai Biomodel Organism Science \& Technology Development Co, Ltd. Ephx2-CreER ${ }^{\mathrm{T} 2}$; ROSA26 tdTomato mice were bred by crossing Ephx2-CreER ${ }^{\mathrm{T} 2}$ mice with ROSA26 tdTomato mice. Transgenic mice were identified by PCR and confirmed by agarose gel electrophoresis. Tamoxifen $(100 \mathrm{mg} / \mathrm{kg}$, dissolved in corn oil) was intraperitoneally injected for 5 consecutive days when mice were 3 months old.

The C57BL/6J mice were obtained from the Laboratory Animal Center of Southern Medical University (Guangzhou, China).

Tissue preparation. Mice were deeply anesthetized with pentobarbital $(80 \mathrm{mg} / \mathrm{kg}$, i.p.) and perfused with $0.9 \%$ saline. The brains were removed from the skull. One hemisphere was frozen immediately for biochemical analysis and the other was fixed in $4 \%$ paraformaldehyde.

Immunofluorescence. The brain tissue preparation and immunohistochemistry were performed according to a standard protocol that is used in our laboratory (Zhu et al., 2010). Brains were perfused with $0.9 \%$ saline, followed by fixation with $4 \%$ paraformaldehyde for $24 \mathrm{~h}$ and incubation in $30 \%$ sucrose for $48 \mathrm{~h}$. Brains were cut into $40 \mu \mathrm{m}$ slices using a freezing microtome (catalog \#CM1850, Leica). Slices were washed with $0.1 \mathrm{M}$ PBS three times for $5 \mathrm{~min}$ and blocked with goat serum containing $0.5 \%$ Triton $\mathrm{X}-100$ for $2 \mathrm{~h}$ at room temperature, followed by incubation with the primary antibody, mouse anti-6E10 (1:1000; catalog \#803001, BioLegend; RRID:AB_2564653), rabbit anti-Iba1 (1:1000; catalog \#019-19741, Wako; RRID:AB_839504), rabbit monoclonal anti-S100 $\beta$ (1:100; catalog \#ab52642, Abcam; RRID:AB_882426), or rabbit polyclone anti-GFAP (glial fibrillary acidic protein; 1:1000; catalog \#AB5804, Millipore; RRID:AB_2109645) at $4^{\circ} \mathrm{C}$ overnight. Slices were then incubated with the corresponding fluorescence-conjugated secondary antibody, Alexa Fluor 594 (1:500; catalog \#A-11005, Thermo Fisher Scientific; RRID:AB_2534073) or Alexa Fluor 488 (1:500; catalog \#A-21206, Thermo Fisher Scientific; RRID:AB_2535792), at room temperature for $2 \mathrm{~h}$. Images were captured by fluorescent microscopy (Nikon Instruments). The $\mathrm{A} \beta$ area fraction, cell counting, and GFAPcovered area were calculated using the software ImageJ (National Institutes of Health). Imaris 8.3 (Bitplane) was used for three-dimensional rendering and analysis of the soma volume.

For detecting transcription factor EB (TFEB) nuclear translocation, primary cultured astrocytes were grown on the coverslips and incubated with 1-trifluoromethoxyphenyl-3-(1-propionylpiperidin4-yl) urea (TPPU; catalog \#11120, Cayman Chemical) or 14,15-EET. Cells were harvested at $0,5,15,30,60$, and $120 \mathrm{~min}$ after TPPU or 14,15 -EET incubation, and fixed in $4 \%$ paraformaldehyde at room temperature for $20 \mathrm{~min}$. After washing with $0.1 \mathrm{~m}$ PBS three times for $5 \mathrm{~min}$, the coverslips were incubated with $0.1 \mathrm{M}$ PBS containing $0.2 \%$ Triton X-100 for 20 min before blocking with goat serum containing $0.3 \%$ Triton $\mathrm{X}-100$ for $1 \mathrm{~h}$ at room temperature. The coverslips were then incubated with primary antibody, rabbit polyclone anti-TFEB (1:200; catalog \#A303-673A, Bethyl Laboratories; RRID: AB_11204751) at $4^{\circ} \mathrm{C}$ overnight. After washing with $0.1 \mathrm{M}$ PBS for $3 \times 5 \mathrm{~min}$, the coverslips were incubated with Alexa Fluor 488 donkey anti-rabbit (1:500; catalog \#A-21 206, Thermo Fisher Scientific; RRID:AB_2535792) at room temperature for $2 \mathrm{~h}$. Images were captured using a Nikon A1R confocal microscope (Nikon Instruments).

Thioflavin S staining. Thioflavin S staining was conducted as reported previously (Heneka et al., 2013). Briefly, sections were rinsed in water and washed with $0.1 \mathrm{~m}$ PBS three times for $5 \mathrm{~min}$. Sections were then incubated in $0.01 \%$ thioflavin $S$ in $50 \%$ ethanol for $8 \mathrm{~min}$ and washed with $50 \%$ ethanol three times for $5 \mathrm{~min}$. Images were captured using fluorescence microscopy (Nikon Instruments). The total plaque number was calculated using the software ImageJ (National Institutes of Health).

Brain protein extraction. Frozen brain hemispheres were extracted as described previously (Kawarabayashi et al., 2001). Briefly, hemispheres were homogenized in $2 \%$ SDS with protease inhibitors, centrifuged at $100,000 \times g$ for $1 \mathrm{~h}$ at $4^{\circ} \mathrm{C}$, and the pellet containing insoluble $\mathrm{A} \beta$ was extracted with $70 \%$ formic acid (FA) in water. Formic acid extracts were neutralized initially by a 1:20 dilution into $1 \mathrm{~m}$ Tris phosphate buffer, $\mathrm{pH} 11$.

ELISA quantification of $A \beta$. Quantitative determination of $\mathrm{A} \beta$ was performed using a solid-phase sandwich ELISA kit for the determination of $\mathrm{A} \beta_{1-40}$ (catalog \#KHB3481, Thermo Fisher Scientific) and $\mathrm{A} \beta_{1-42}$ (catalog \#KHB3441, Thermo Fisher Scientific) according to the protocol of the supplier. Briefly, $50 \mu \mathrm{l}$ of standard $\mathrm{A} \beta$ of gradient concentration and protein samples were added to the $\mathrm{A} \beta$ antibody-bedded plate, and 
$50 \mu \mathrm{l}$ of detection antibody was then added. After incubation overnight at $4^{\circ} \mathrm{C}$, the liquid was discarded, and the wells were washed four times for at least $30 \mathrm{~s}$. Then, $100 \mu \mathrm{l}$ of anti-rabbit HRP working solution was added to the wells and incubated for $30 \mathrm{~min}$ at room temperature, followed by $100 \mu \mathrm{l}$ of stabilized chromogen incubation for $30 \mathrm{~min}$ at room temperature in the dark. Stop solution $(100 \mu \mathrm{l})$ was added, and the absorbance of each well was read at a $450 \mathrm{~nm}$ wavelength using the VICTOR X3 Multilabel plate reader (PerkinElmer). A four-parameter algorithm was used for standard curve fitting, and sample $\mathrm{A} \beta$ concentration was calculated.

Western blotting. Tissues were lysed using a homogenized buffer containing $25 \mathrm{~mm}$ Tris-HCl, pH 7.6, $150 \mathrm{~mm} \mathrm{NaCl}, 1 \% \mathrm{NP}-40,1 \%$ sodium deoxycholate, $1 \%$ SDS, and protease inhibitor cocktail. The lysates were centrifuged at $14,000 \times g$ for $20 \mathrm{~min}$ at $4^{\circ} \mathrm{C}$, and the supernatant was collected. Protein concentrations were determined by the Bradford method. Proteins were boiled in loading buffer for $10 \mathrm{~min}$, and $60 \mu \mathrm{g}$ of protein was loaded onto a 10\% [for APP, APP N-terminal fragment (NTF), and lysosomal-associated membrane protein 1 (Lamp1) detection] or $15 \%$ [for APP C-terminal fragments (CTFs) and 6E10 detection] SDS-PAGE gel, transferred to a polyvinylidene fluoride membrane, blocked with $5 \%$ milk for $1 \mathrm{~h}$ at room temperature, and then incubated with the primary antibody overnight at $4^{\circ} \mathrm{C}$. The primary antibodies used were as follows: anti-APP Cterminal fragment monoclonal antibody (1:1000; catalog \#SIG-39152-200, Covance; RRID:AB_10717336), anti-APP-NTF (1:1000; catalog \#A8967, Sigma-Aldrich; RRID:AB_258427), mouse anti-6E10 (1:1000; catalog \# 803001, BioLegend; RRID:AB_2564653), mouse anti-Lamp1 (1:1000; cata$\log \# 1 \mathrm{~d} 4 \mathrm{~b}$, Developmental Studies Hybridoma Bank; RRID:AB_2134500), and mouse anti-GAPDH (1:10,000, catalog \#AB-P-R001, Hangzhou Goodhere Biotech Co., Ltd). The protein bands were analyzed using FluorChem SP software (Alpha Innotech).

Quantitative real-time RT-PCR. RNA was extracted from the cerebral cortex of male $5 \times \mathrm{FAD}$; Eph $x 2^{-/-}$mice and control littermates, or from BV2 cells treated with 14,15-EET or solvent using RNAiso Plus (catalog \#D9108A, Takara) according to the manufacturer instructions. The total RNA was spectrophotometrically quantified and reverse transcribed into complementary DNA using the PrimeScript RT Reagent Kit (catalog \#RR037A, Takara). Quantitative real-time PCR (qRT-PCR) was performed using SYBR Premix Ex Taq (catalog \#RR420A, Takara) on the 7500 Real-Time PCR system (Thermo Fisher Scientific). Samples were assayed in triplicate. The ribosomal protein S18 gene was used as housekeeping reference. The $2^{-\Delta \Delta \mathrm{Ct}}$ method was used to determine relative expression levels of each amplification. The primers used in this study are listed in Table 1.

EET measurements. Ultra-performance liquid chromatography-tandem mass spectrometry (UPLC-MS/MS) analysis was performed according to our previous report (Zhang et al., 2018). Briefly, the cerebral cortex and hippocampus (Hip.) were added to 10-fold PBS, pH 7.4, and homogenized for $1 \mathrm{~min}\left(4^{\circ} \mathrm{C}, 6500 \mathrm{rpm}\right.$; Precellys 24-Dual Homogenizer, Bertin Technologies). The suspension, containing $800 \mathrm{~nm}$ TPPU (catalog \#1222780-33-7, Cayman Chemical), was added at an equal volume to the mixture methanol:acetonitrile:acetic acid (50/50/ $0.02 \%, \mathrm{v} / \mathrm{v} / \mathrm{v})$, containing internal standard $(20 \mathrm{ng} / \mathrm{ml})$, and vortexed for $10 \mathrm{~min}$. The mixture was centrifuged at $5000 \mathrm{rpm}\left(4^{\circ} \mathrm{C}\right)$ for $1 \mathrm{~min}$, precipitated for $2 \mathrm{~h}\left(-20^{\circ} \mathrm{C}\right)$, and centrifuged at $14,000 \mathrm{rpm}\left(4^{\circ} \mathrm{C}\right)$ for $10 \mathrm{~min}$. The filtrate was collected for UPLC-MS/MS analysis (Thermo Fisher Scientific).

BV2 cell culture. The mouse microglia cell line (BV2) was purchased from the Cell Resource Center, Institute of Basic Medical College, Chinese Academy of Medical Sciences, People's Republic of China (cata$\log \# 3111$ C0001CCC000063). The BV2 cells were cultured in DMEM containing $10 \%$ fetal bovine serum, $100 \mathrm{U} / \mathrm{ml}$ penicillin and $100 \mu \mathrm{g} / \mathrm{ml}$ streptomycin. BV2 cells were treated with 14,15-EET ( $1 \mu \mathrm{M}$, dissolved in ethanol) or solvent ( $1 \%$ ethanol at final concentration) for $3 \mathrm{~h}$, and harvested for $\mathrm{qRT}$-PCR examination.

Adult primary astrocytes culture. Primary adult mouse astrocytes were prepared as previously described (Cao et al., 2013a), with some modifications. Cerebral cortex was obtained from 6- to 8-week-old C57BL/6J mice or Eph $x 2^{-1-}$ mice and their control littermates, and digested in $\mathrm{Ca}^{2+}$-free and $\mathrm{Mg}^{2+}$-free HBSS with $0.25 \%$ trypsin and
Table 1. Primer sequences used for quantitative real-time PCR

\begin{tabular}{|c|c|c|}
\hline$\overline{\text { Gene }}$ & Forward primer & Reverse primer \\
\hline Bace1 & ACAACCTGAGGGGAAAGTCC & TACTACTGCCCGTGTCCACC \\
\hline Nos2 & GTGTTCCACCAGGAGATGTTG & CTCCTGCCCACTGAGTTCGTC \\
\hline Tnf & TCTTCTCATTCCTGCTTGTGG & GGTCTGGGCCATAGAACTGA \\
\hline 116 & TAGTCCTTCCTACCCCAATTTCC & TTGGTCCTTAGCCACTCCTTC \\
\hline $\operatorname{Tgfb2}$ & GCGAGCGAAGCGACGAGGAG & TGGGCGGGATGGCATCAAGGTA \\
\hline$\| 10$ & GTTACTTGGGTTGCCAAG & TTGATCATCATGTATGCTTC \\
\hline$B 2 m$ & TGGCTCACACTGAATTCACCCCCA & TCTCGATCCCAGTAGACGGTCTTGC \\
\hline Icam 1 & AGATCACATTCACGGTGCTGGCTA & AGCTTTGGGATGGTAGCTGGAAGA \\
\hline Bst2 & TGTTCGGGGTTACCTTAGTCA & GCAGGAGTTTGCCTGTGTCT \\
\hline Trem2 & AGGGCCCATGCCAGCGTGTGGT & CCAGAGATCTCCAGCATC \\
\hline$C d 33$ & TGTTTTCTACCCCTCCATTAAGC & TCTCTGATGAACAGGGAACAGT \\
\hline Fth1 & GATCAACCTGGAGTTGTATGCC & CTCCCAGTCATCACGGTCTG \\
\hline Tmem119 & GTGTCTAACAGGCCCCAGAA & AGCCACGTGGTATCAAGGAG \\
\hline$C d 68$ & CCAATTCAGGGTGGAAGAAA & CTCGGGCTCTGATGTAGGTC \\
\hline Lyz1 & CGTTGTGAGTTGGCCAGAA & GCTAAACACACCCAGTCAGC \\
\hline Lyz2 & TGAACGTTGTGAGTTTGCCA & TGAGCTAAACACACCCAGTCG \\
\hline Mcoln1 & GCTGGGTTACTCTGATGGGTC & CCACCACGGACATAGGCATAC \\
\hline Mcoln2 & TCAGGAGAACACCTATGAGAGC & CCAAGGGTTGCCAGGGAAAT \\
\hline Mcoln3 & GCTACATGGATCGAATGGACG & СCCTTGTTCTCATAAGCGTGATT \\
\hline Atp6v0d1 & GCATCTCAGAGCAGGACCTTGA & GGATAGGACACATGGCATCAGC \\
\hline Atp6v1h & GTTGCTGCTCACGATGTTGGAG & TGTAGCGAACCTGCTGGTCTTC \\
\hline Ctsa & TTCTGATCCAGCCAGATGGTG & TACAGCACGTTGGCAATCAGG \\
\hline Ctsb & TTAGCGCTCTCACTTCCACTACC & TGCTTGCTACCTTCCTCTGGTTA \\
\hline Ctsd & CGTCCTTTGACATCCACTACGG & TGGAACCGATACAGTGTCCTGG \\
\hline Ctsf & ACGCCTATGCAGCCATAAAG & CTTTTGCCATCTGTGCTGAG \\
\hline Clcn7 & AGAAAGTGTCTTGGTCCGGC & AGTGCAGAATGAGACTGGCG \\
\hline Gns & ACCTGACAGATGTTCTGGCCA & CGCTGGAGTGGAGATCATCAT \\
\hline Lamp1 & CCTACGAGACTGCGAATGGT & CCACAAGAACTGCCATTTTTC \\
\hline Mcoln1 & GCGCCTATGACACCATCAA & TATCCTGGCACTGCTCGAT \\
\hline Sgsh & CCTGCTGCACAATTCTGTTGG & TCCGTCATCCGCAACTATCAG \\
\hline Tpp1 & AAGCCAGGCCTACATAGTCAGA & CCAAGTGCTTCCTGCAGTTTAGA \\
\hline Rps18 & AGTTCCAGCACATTTTGCGAG & TCATCCTCCGTGAGTTCTCCA \\
\hline
\end{tabular}

$1 \mathrm{~mm}$ EDTA (catalog \#SM-2003-C, Millipore) for $30 \mathrm{~min}$ at $37^{\circ} \mathrm{C}$. The suspension was triturated with $10 \mathrm{mg} / \mathrm{ml}$ DNase I (catalog \# 10104159001, Roche) and growth medium (DMEM/F12 medium containing $15 \%$ fetal bovine serum, $100 \mathrm{U} / \mathrm{ml}$ penicillin, and $100 \mu \mathrm{g} / \mathrm{ml}$ streptomycin). The cells were centrifuged at $1500 \mathrm{rpm}$ for $5 \mathrm{~min}$ and then filtered through a $100 \mu \mathrm{m}$ cell strainer (catalog \#352360, Becton Dickinson). Dissociated cells were resuspended in growth medium and G5 supplement was added to establish primary culture.

$A \beta$ removal assay. Fluorescein isothiocyanate (FITC)-A $\beta_{42}$ (catalog\#H-7666, BACHEM) was solved in $N, N$-dimethylformamide (catalog \#D8360, Beijing Solarbio Science \& Technology Co., Ltd.) at a concentration of $1 \mathrm{mg} / \mathrm{ml}$. Glass slides were coated with poly-L-lysine (0.1 mg/ml; catalog \# 25 988-63-0, Sigma-Aldrich) overnight, washed with sterile water, and air dried. Glass slides were incubated with $\mathrm{DMEM} / \mathrm{F} 12$ containing $10 \mu \mathrm{g} / \mathrm{ml}$ FITC-A $\beta_{42}$ at $37^{\circ} \mathrm{C}$ for $2 \mathrm{~h}$, then washed with sterile water and air dried. Astrocytes suspended in growth medium were plated on FITC-A $\beta_{42}$-coated glass slides $\left(5 \times 10^{4}\right.$ cells/ $500 \mu \mathrm{l}$, per glass slide). Four hours later, vehicle, $\operatorname{TPPU}(25,50$, and 100 $\mu \mathrm{M}$ final concentrations), 14,15 -EET $(0.1,1$, and $10 \mu \mathrm{M}$ final concentrations; catalog \#50 651, Cayman Chemical), 5,6-EET ( $1 \mu \mathrm{M}$ final concentration; catalog \#50211, Cayman Chemical), 8,9-EET (1 $\mu \mathrm{M}$ final concentration; catalog \#50351, Cayman Chemical), or 11,12-EET (1 $\mu \mathrm{M}$ final concentration; catalog \#50511, Cayman Chemical) was added to the cultured medium, and, 1 or $4 \mathrm{~h}$ later, astrocytes were washed with 0.1 м PBS three times. After incubation with LysoTracker Red (1:5000; catalog \#L7528, Thermo Fisher Scientific) for $45 \mathrm{~min}$, astrocytes were washed and fixed in $4 \%$ paraformaldehyde. The glass slides were then washed and mounted with a Vectashield mounting medium (Vector Laboratories) containing DAPI. Images were captured by fluorescence microscopy (Nikon Instruments) and analyzed using ImageJ software (National Institutes of Health).

$A \beta$ degradation assay. This assay was conducted as reported previously (Wyss-Coray et al., 2003). Briefly, A $\beta_{42}$ (catalog \#H-1368, 
A
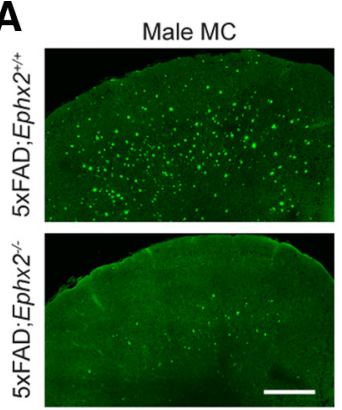

B
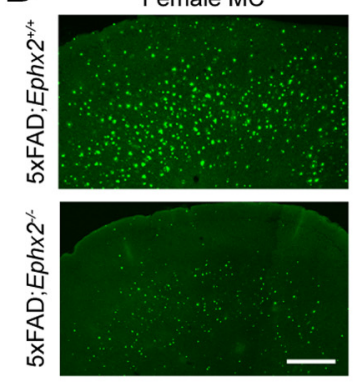

C
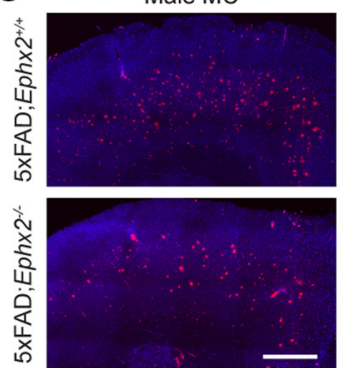

G

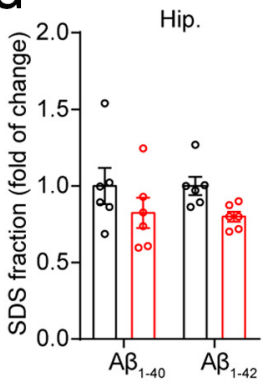

Male Hip.

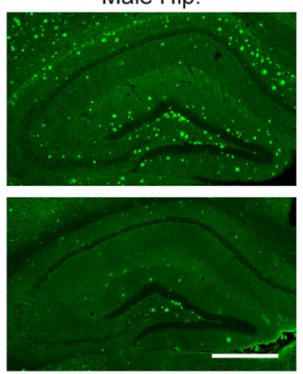

Female Hip.
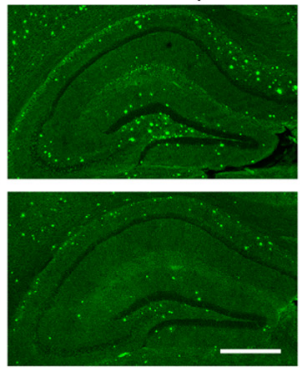

Male Hip.
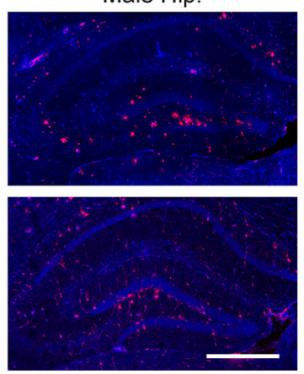

H
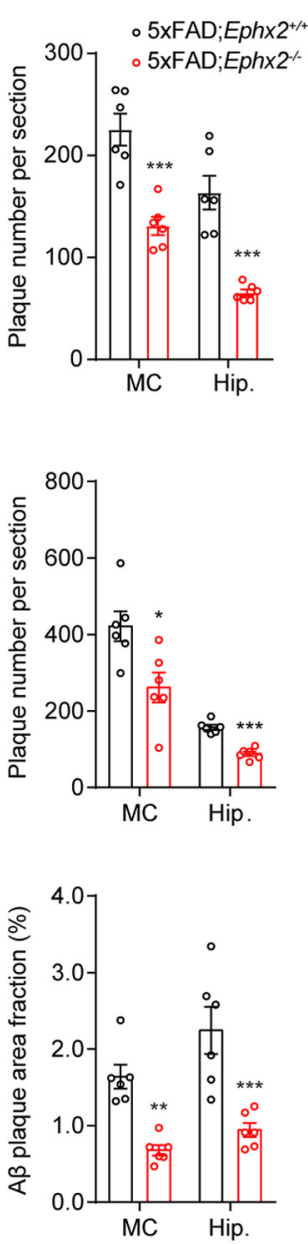

D

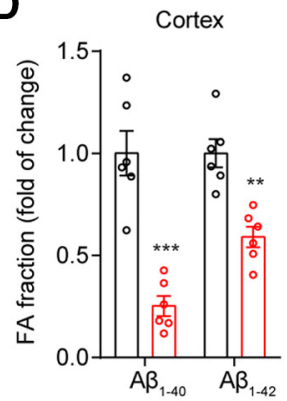

E

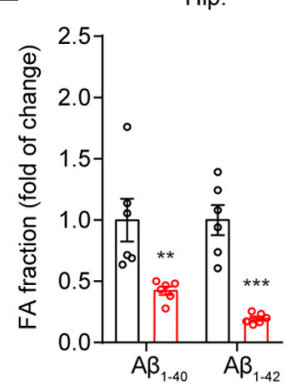

$\mathbf{F}$

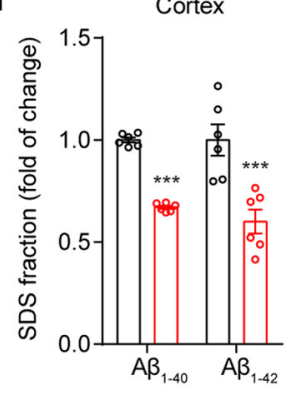

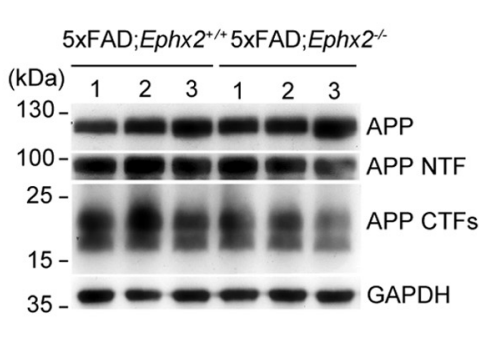

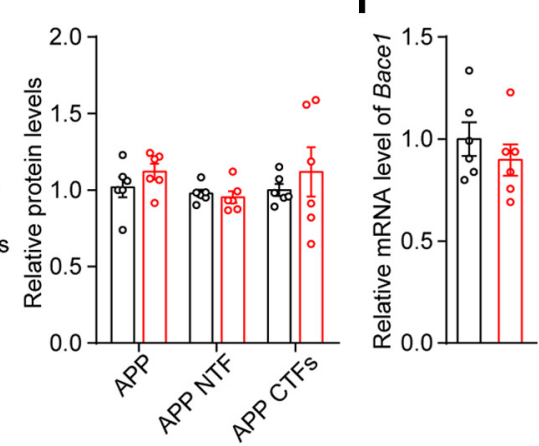

Figure 1. Ephx2 deletion alleviates $A D$ pathology in $5 \times F A D$ mice. $\boldsymbol{A}, \boldsymbol{B}$, Representative images and quantitative analysis of thioflavin $S$ staining in 6-month-old male $(\boldsymbol{A})$ and female $(\boldsymbol{B})$ $5 \times$ FAD mice $(n=6)$. C, Representative images and quantitative analysis of $A \beta$ immunolabeling in 6-month-old male $5 \times$ FAD mice $(n=6)$. $\boldsymbol{D}-\boldsymbol{G}$, Brain levels of insoluble $(\boldsymbol{D}, \boldsymbol{E})$ and soluble $(\boldsymbol{F}, \boldsymbol{G}) \mathrm{A} \beta_{1-42}$ and $\mathrm{A} \beta_{1-40}$ in the cerebral cortex (Cortex) and Hip. $(n=6)$. $\boldsymbol{H}$, Western blot analysis of protein levels of APP and its cleavage products in the cortex of $5 \times F A D ; E p h \times 2^{-1-}$ mice and control littermates $(n=6 ; 1,2$, and 3 indicate three independent biological samples). $I$, The mRNA levels of $\beta$-Secretase 1 (Bace1) in the cerebral cortices of 6-month-old male $5 \times F A D$; Ephx $2^{-1-}$ mice and control littermates $(n=6)$. Scale bar, $500 \mu \mathrm{m}$. Data are presented as the mean \pm SEM. ${ }^{*} p<0.05,{ }^{* *} p<0.01,{ }^{* * *} p<0.001$.

BACHEM) was dissolved in $0.1 \% \mathrm{NH}_{4} \mathrm{OH}$ at a concentration of $1 \mathrm{mg} / \mathrm{ml}$ and incubated at $37^{\circ} \mathrm{C}$ for $2 \mathrm{~h}$. Astrocytes were directly or pretreated with ML-SI3 $(25 \mu \mathrm{M}, 10 \mathrm{~min}$; donated by Professor Haoxing $\mathrm{Xu}$, Department of Molecular, Cellular, and Developmental Biology, University of Michigan) and then exposed to $2 \mu \mathrm{g} / \mathrm{ml} \mathrm{A} \beta_{42}$ followed by the application of vehicle, TPPU $(25,50$, and $100 \mu \mathrm{M}$, final concentrations), 14,15-EET $(0.1,1$, and $10 \mu \mathrm{M}$ final concentrations), 5,6-EET, 8,9-EET, or 11,12-EET ( $1 \mu \mathrm{M}$ final concentrations) into the cultured medium. Astrocytes were harvested 1 or $4 \mathrm{~h}$ later, and $\mathrm{A} \beta$ levels in cultured medium and cell pellets were determined by Western blot.

Osmotic minipump implantation. Osmotic minipump implantation assay was performed as described in a previous report (Cao et al., 2013b). Briefly, $5 \times$ FAD mice were anesthetized, and an osmotic pump (model 1007D, Alzet) was implanted in the right hippocampal dentate gyrus $(D G$; anteroposterior $=-2.0$, mediolateral $=1.2 \mathrm{~mm}$, dorsoventral $=2.0 \mathrm{~mm}$ ). The osmotic pumps are designed to deliver a flow rate of $0.5 \mu \mathrm{l} / \mathrm{h}$ for $7 \mathrm{~d}$ and were filled with artificial CSF (ACSF; vehicle) or 14,15-EET (100 ng/ml) dissolved in ACSF. Brain tissues were prepared $7 \mathrm{~d}$ after the pump implantation. The concentration of 14,15 -EET $(100 \mathrm{ng} / \mathrm{ml})$ was determined as follows: the concentration of FA fraction $\mathrm{A} \beta_{42}$ in 3 -month-old $5 \times \mathrm{FAD}$ male mice, which was $\sim 50 \mathrm{pmol} / \mathrm{g}$ (equal to $20 \mathrm{ng} / \mathrm{ml}$ ). To avoid the metabolic losses in vivo, the final concentration of 14,15 -EET $(100 \mathrm{ng} / \mathrm{ml})$ was selected. 
A

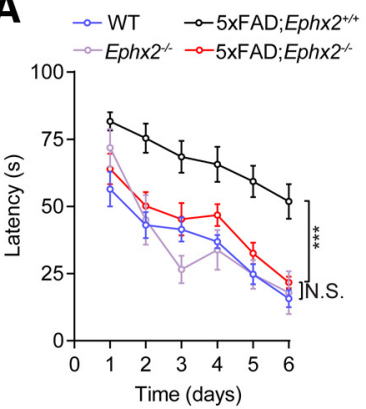

F

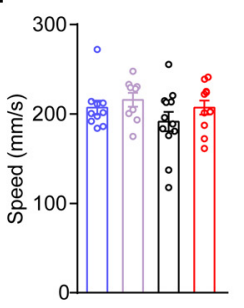

B

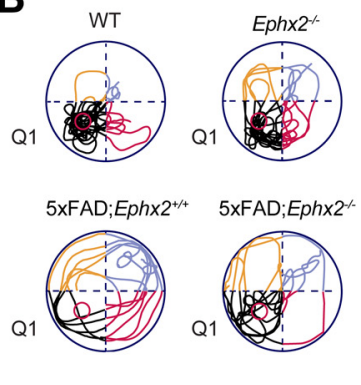

H

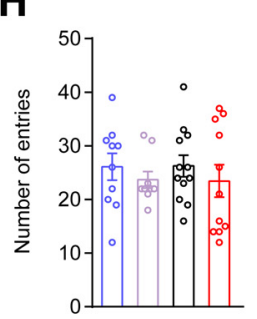

D

C

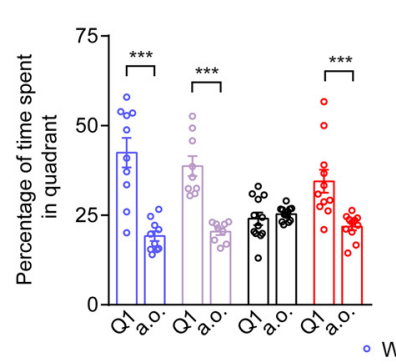

E

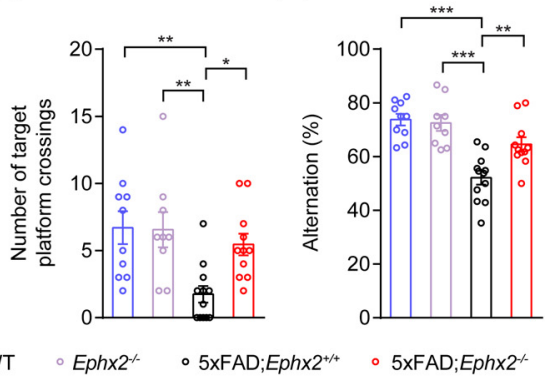

G

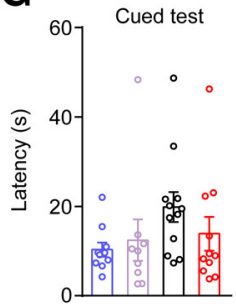

I

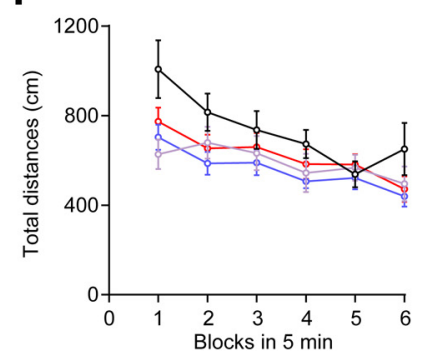

J

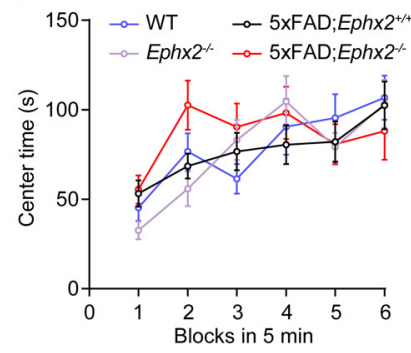

Figure 2. Ephx2 deletion improves cognitive performance in $5 \times F A D$ mice. $\boldsymbol{A}-\boldsymbol{D}$, Behavioral analysis with the MWM test $(n=9-12)$. $\boldsymbol{A}$, Acquisition training. $\boldsymbol{B}$, Representative traces of swimming paths in the probe trial; $Q 1$, target quadrant in which the platform was located on days $1-6$. $C$, Time spent in $Q 1$ and all other (a.0.) quadrants. $\boldsymbol{D}$, The number of platform crossings in the probe trial (one-way ANOVA). $\boldsymbol{E}$, Behavioral analysis with the Y-maze $(n=9-12) . \boldsymbol{F}$, Velocity of mice in the MWM (WT, $n=10 ;$ Ephx $2^{-1-}, n=9 ; 5 \times \mathrm{FAD}$;Ephx $2^{+/+}, n=12$; and $5 \times \mathrm{FAD} ; E$ Ephx $\left.2^{-1-}, n=11\right) . \mathbf{G}$, Latency in the cued test (WT, $n=10 ; \mathrm{Ephx}^{-1-}, n=9 ; 5 \times \mathrm{FAD} ; \mathrm{Ephx} 2^{+/+}, n=12$; and $\left.5 \times \mathrm{FAD} ; \mathrm{Ephx} 2^{-1-}, n=11\right)$. $\boldsymbol{H}$, Number of entries in the Y-maze

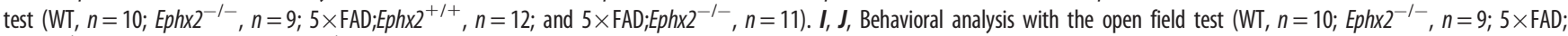

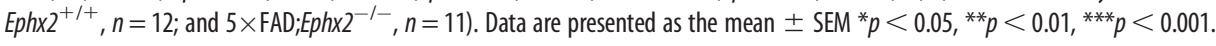

Open field. Mice were placed in an open chamber (AccuScan Instruments) with transparent plastic walls and were allowed to explore freely for 5 or $30 \mathrm{~min}$. The total distance traveled across a session was analyzed using VersaMax analyzer software (AccuScan Instruments).

Morris water maze test. The water maze consisted of a circular tank $(\varnothing 1 \mathrm{~m})$ containing opaque water $\left(21 \pm 1^{\circ} \mathrm{C}\right)$. The maze was divided virtually into four quadrants, with one containing a hidden platform $(\varnothing 10$ $\mathrm{cm})$ present $1 \mathrm{~cm}$ below the water surface. Mice were trained to find the platform, orienting by three extra-maze cues placed asymmetrically as spatial references. During acquisition, animals were placed into the water in a quasi-random fashion to prevent strategy learning. Mice were allowed to search for the platform for $90 \mathrm{~s}$; if the mice failed to identify the platform within $90 \mathrm{~s}$, they were guided gently onto the platform and allowed to stay there for $30 \mathrm{~s}$ before the initiation of the next trial. After the completion of four trials, mice were dried and placed back into their home cages. Mice were trained for four trials per day for 6 consecutive days. Escape latency was measured as the time taken for the animal to locate the hidden platform in the target quadrant Q1. For spatial probe trials, which were conducted $24 \mathrm{~h}$ after the last training session (day 7 ), the platform was removed and mice were allowed to swim for $90 \mathrm{~s}$. The drop position was at the border between the third and fourth quadrant, with the mouse facing the wall at the start. Data are given as the percentage of time spent in quadrant Q1, the number of platform crossings, and the swimming speed. In the afternoon of the same day, visual cued testing was performed with the platform being flagged and new positions for the start and goal during each trial. Swimming behavior was captured by a camera (model WVBP334, Panasonic), and the video signal was analyzed using EthoVision 7.0 (Noldus Information Technology).

$Y$-maze test. The Y-maze was made of gray Plexiglas and had three identical arms of $30 \times 10 \times 20 \mathrm{~cm}$ and a center area connected to the three arms by a triangle of $10 \times 10 \times 10 \mathrm{~cm}$. Each arm formed a $120^{\circ}$ angle with the other two arms. Mice were administered one trial per day for 3 consecutive days. During a trial, mice were placed in the central area and allowed to explore the maze freely for $5 \mathrm{~min}$. The order in which the mice chose to enter the arms was recorded. Three consecutive choices, all with different arms, were counted as an alternation and were scored with 1 point. The total number of opportunities for alternation was calculated as the total number of arm entries minus two. The percentage correct rate $=$ (total alternation points/total alternation opportunities $) \times 100$. For example, if a mouse chose the arms in the order $\mathrm{ABCACBACBC}$, then the percentage correct rate $=$ $[6 /(10-2)] \times 100=75 \%$. The Y-maze was wiped clean between trials with $70 \%$ ethanol.

Experimental design and statistical analyses. All the data were analyzed by GraphPad Prism 8.2 (GraphPad Software) and are presented as the mean \pm SEM. Two-tailed $t$ test or multiple $t$ test with Bonferroni correction was used to compare the differences between two groups (one-way or two-way ANOVA, followed by Bonferroni's test for comparisons among more than two groups). Repeated-measures ANOVA were used to analyze the data collected from an individual at different times. $p<0.05$ was considered significant, and the significance was set at $95 \%$ confidence.

\section{Results}

\section{Ephx2 deletion alleviates pathologic features in AD model} mice

To investigate whether sEH is involved in the pathophysiology of $\mathrm{AD}$, we characterized the overall effect of Ephx2 deletion on $\mathrm{A} \beta$ pathology and the associated behavioral responses. To this end, Eph $x 2^{-l-}$ mice were crossed with $5 \times \mathrm{FAD}$ mice to obtain 5 $\times \mathrm{FAD}$;Eph $\times 2^{-1-}$ mice. In $5 \times \mathrm{FAD}$ mice, while $\mathrm{A} \beta$ plaques appeared at $2-3$ months of age, behavioral deficits in spatial learning were initiated at $\sim 6$ months (Oakley et al., 2006). Therefore, experiments were performed on 6-month-old mice. Thioflavin S staining of matched coronal brain sections showed a marked decrease in the motor cortex (MC) and Hip. A $\beta$ deposition in $5 \times \mathrm{FAD}$;Eph $\times 2^{-1-}$ mice compared with sex-matched $5 \times \mathrm{FAD}$;Eph $\times 2^{+/+}$littermates (Fig. $1 A, B$; male: MC, $t_{(20)}=5.409$, $p<0.001$; Hip., $t_{(20)}=5.619, p<0.001$; female: MC, $t_{(20)}=2.9$, $p=0.032$; Hip., $t_{(20)}=7.822, p<0.001$, multiple $t$ tests following Bonferroni correction). In addition, the reduced $\mathrm{A} \beta$ plaques were further quantified using anti-A $\beta$ (6E10) immunostaining (Fig. $1 C$; male: MC, $t_{(20)}=3.726, p=0.003$; Hip., $t_{(20)}=5.047$, 
A
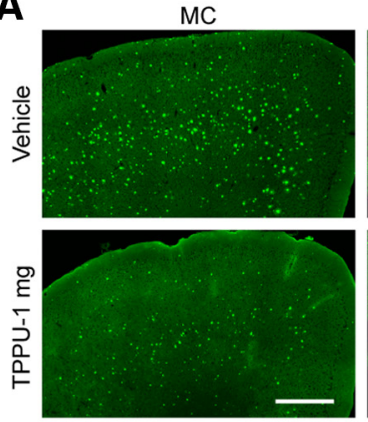

C
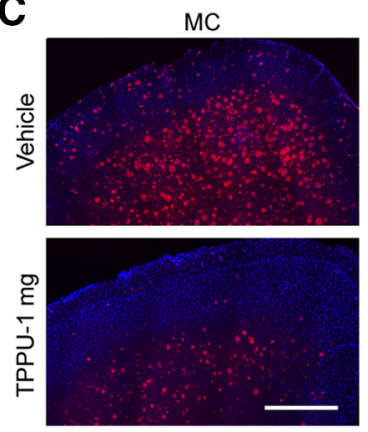

E

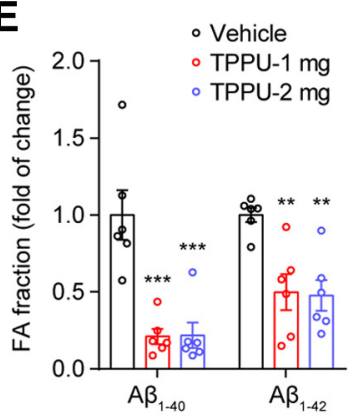

Hip.
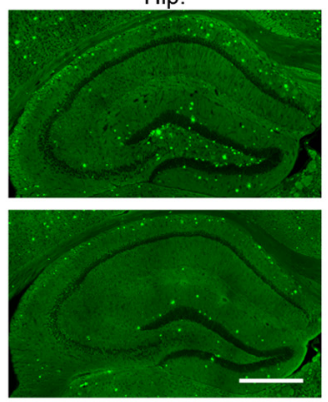

Hip

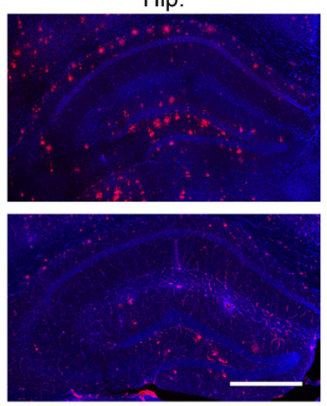

$\mathbf{F}$

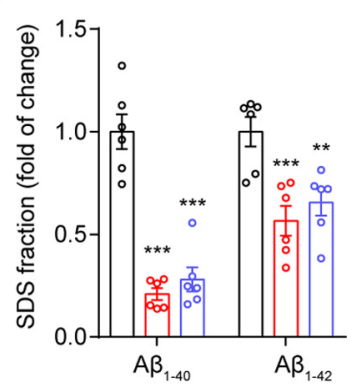

D
B

$\mathrm{MC}$
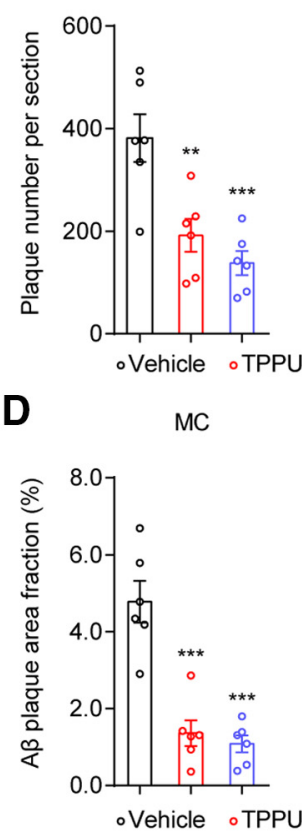

G

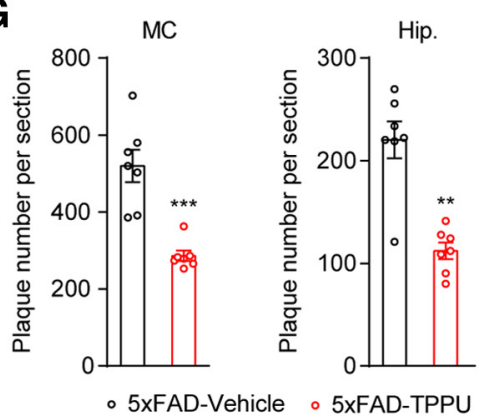

Figure 3. TPPU treatment reduces brain $A \beta$ deposition in $5 \times F A D$ mice. $A, B$, Representative images of thioflavin $S$ staining and quantification of plaques in the MC and Hip. of 6-monthold male $5 \times$ FAD mice treated with vehicle or TPPU for $14 \mathrm{~d}(n=6)$. $\boldsymbol{C}, \boldsymbol{D}$, Representative images of A $\beta$ immunolabeling and quantitative analysis $(n=6)$. $\boldsymbol{E}, \boldsymbol{F}$, ELISA-based detection and quantification of $A \beta_{1-42}$ and $A \beta_{1-40}$ in the FA and SDS fractions of the Hip. in $5 \times$ FAD mice $14 \mathrm{~d}$ after treatment with TPPU or vehicle $(n=6)$. G, Effect of TPPU on $A \beta$ accumulation in 6-month-old female $5 \times$ FAD mice $(n=7)$. Scale bar, $500 \mu \mathrm{m}$. Data are presented as the mean \pm SEM. ${ }^{*} p<0.05,{ }^{* *} p<0.01,{ }^{* * *} p<0.001$.

$p<0.001$, multiple $t$ tests following Bonferroni correction). Moreover, the brain levels of soluble and insoluble $\mathrm{A} \beta$ were analyzed using ELISA. $5 \times \mathrm{FAD}$;Eph $\times 2^{-/-}$mice showed reduced brain concentrations of the FA-extractable forms of $\mathrm{A} \beta_{1-40}$ and $\mathrm{A} \beta_{1-42}$ (Fig. $1 D, E$; cortex: $\mathrm{A} \beta_{1-40}, t_{(20)}=7.188, p<0.001$; $\mathrm{A} \beta_{1-42}, t_{(20)}=3.935, p=0.002$; Hip.: $\mathrm{A} \beta_{1-40}, t_{(20)}=3.766$, $p=0.002 ; \mathrm{A} \beta_{1-42}, t_{(20)}=5.266, p<0.001$, multiple $t$ tests following Bonferroni correction) and moderate reductions in SDSsoluble $\mathrm{A} \beta_{1-40}$ and $\mathrm{A} \beta_{1-42}$ levels (Fig. $1 F, G$; cortex: $\mathrm{A} \beta_{1-40}$, $t_{(20)}=4.807, p<0.001 ; \mathrm{A} \beta_{1-42}, t_{(20)}=5.812, p<0.001$; Hip.: $\mathrm{A} \beta_{1-40}, t_{(20)}=1.477, p=0.310 ; \mathrm{A} \beta_{1-42}, t_{(20)}=1.683, p=0.216$, multiple $t$ tests following Bonferroni correction). These decreases were not because of changes in APP expression and processing, as the levels of APP and its cleavage products (i.e., the N-terminal and C-terminal fragments) and $\beta$-secretase $1 \mathrm{mRNA}$ levels in the cerebral cortex were indistinguishable between the two groups (Fig. 1H,I; APP, $t_{(30)}=0.917, p>0.999$; NTFs, $t_{(30)}=$ $0.229, p>0.999$; CTFs, $t_{(30)}=1.081, p=0.865$, multiple $t$ tests following Bonferroni correction; Bace1, $t_{(10)}=0.9005, p=0.389$, unpaired $t$ test), indicating comparable $\mathrm{A} \beta$ production. Thus, Ephx2 deficiency prevents $\mathrm{A} \beta$ deposition in the brain of $5 \times \mathrm{FAD}$ mice mainly by inhibiting the formation of insoluble $\mathrm{A} \beta$.
High $\mathrm{A} \beta$ levels in the brains of $5 \times \mathrm{FAD}$ mice are correlated with cognitive and behavioral deficits (Oakley et al., 2006). We assessed spatial memory function in male Eph $x 2^{-/-}, 5 \times \mathrm{FAD}$; Eph $\times 2^{+/+}$, and $5 \times \mathrm{FAD} ; E p h \times 2^{-/-}$mice and their wild-type (WT) littermates with the Morris water maze (MWM) test. While Eph $x 2^{-1-}$ mice showed comparable performance to the WT littermates in the acquisition phase and probe trial, $5 \times \mathrm{FAD}$; Eph $\times 2^{+/+}$mice exhibited severe deficits. In contrast, $5 \times \mathrm{FAD}$; Eph $\times 2^{-1-}$ mice showed no spatial memory impairment (Fig. $2 A-D$; Morris water maze latency, $F_{(10,9,12,11)}=20.480, p<$ 0.001, repeated-measures ANOVA; percentage of time spent in quadrant: WT, $t_{(18)}=5.359, p<0.001 ; E p h \times 2^{-/-}, t_{(16)}=6.162$, $p<0.001 ; 5 \times \mathrm{FAD} ; E p h \times 2^{+/+}, t_{(22)}=0.720, p>0.999 ; 5 \times \mathrm{FAD}$; Eph $x 2^{-1-}, t_{(20)}=3.727, p=0.005$, multiple $t$ tests following Bonferroni correction; number of target platform crossings: $F_{(3,38)}=5.962, p=0.002$, one-way ANOVA). These results were supported by the results of the Y-maze test (Fig. 2E; Y-maze alternation, $F_{(3,38)}=15.66, p<0.001$, one-way ANOVA). There were no differences between groups in the velocity, cued, and open field tests (Fig. $2 F-J$; speed test, $F_{(3,38)}=1.319, p=0.282$; cued test, $F_{(3,38)}=1.448, p=0.224$; Y-maze number of entries, $F_{(3,38)}=0.4076, p=0.748$, one-way ANOVA; open field-total 
A
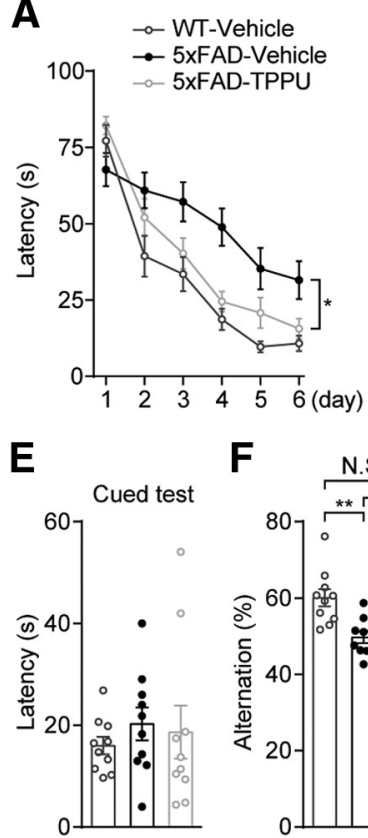

B

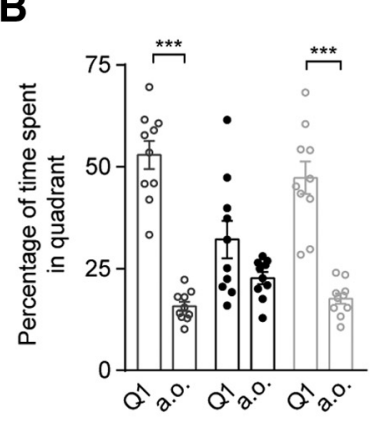

G

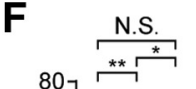

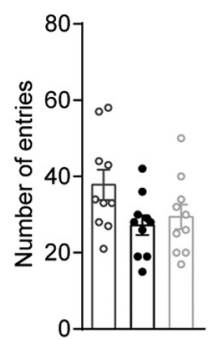

C

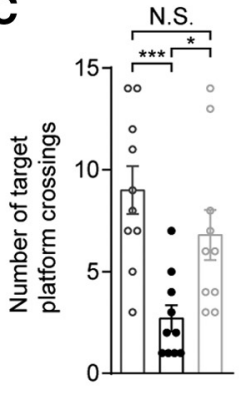

D

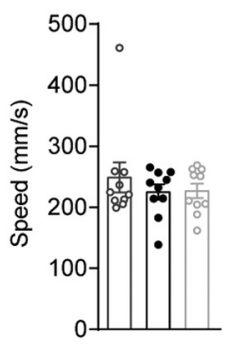

Figure 4. Improvement in behavioral tests with TPPU in $5 \times F A D$ mice. $\boldsymbol{A}-\boldsymbol{E}$, Behavioral analysis with the MWM test $(n=10)$. $\boldsymbol{A}$, Acquisition training (repeated measures). $\boldsymbol{B}$, Time spent in Q1 and all other (a.o.) quadrants. $\boldsymbol{C}$, Number of platform crossings in the probe trial. $\boldsymbol{D}$, Velocity of mice in the MWM. $\boldsymbol{E}$, Latency in the cued test. $\boldsymbol{F}, \boldsymbol{G}$, Behavioral analysis with the $\mathbf{Y}$-maze test $(n=10)$. $\boldsymbol{F}$, Percentage of alternation in the Y-maze test. $\boldsymbol{G}$, Number of entries in the $Y$-maze test. $\boldsymbol{H}, \boldsymbol{I}$, TPPU treatment had no effect on locomotion in the open field test $(n=10)$. Data are presented as the mean \pm SEM. ${ }^{*} p<0.05,{ }^{* *} p<0.01,{ }^{* * *} p<0.001$, N.S., not significant.

distances, $F_{(10,9,12,11)}=1.821, p=0.160$; center time, $F_{(10,9,12,11)}=0.276, p=0.843$, repeated-measures ANOVA). These results were supported by a recent report (Lee et al., 2019), in which genetic deletion of sEH delayed the progression of $\mathrm{AD}$ pathology in an APP/PS1 mouse model. Together, these data indicate that the deletion of Eph $\times 2$ alleviates pathologic features in mouse models of $\mathrm{AD}$.

\section{sEH inhibition reduces brain $\mathrm{A} \beta$ deposition in AD model mice}

We then considered whether inhibition of $\mathrm{sEH}$ could reverse the pathophysiology of $\mathrm{AD}$. To this end, 6-month-old $5 \times \mathrm{FAD}$ mice were injected intraperitoneally for $14 \mathrm{~d}$ with the sEH inhibitor TPPU (1-2 mg/kg; Kodani and Hammock, 2015). Thioflavin S staining of matched coronal brain sections revealed that TPPU decreased $A \beta$ deposition in the MC and Hip. of these mice compared with vehicle-treated, sex-matched littermates (Fig. $3 A, B$; MC, $F_{(2,15)}=13.13$, $p<0.001$; Hip., $F_{(2,15)}=40.52, p<$ 0.001 , one-way ANOVA). The reduction in $\mathrm{A} \beta$ plaque formation was quantified by A $\beta$ (6E10) immunolabeling (Fig. 3C, $D$; MC, $F_{(2,15)}=27.94, p<0.001$; Hip.,

$F_{(2,15)}=27.27, p<0.001$, one-way ANOVA), and brain levels of soluble and insoluble $\mathrm{A} \beta$ were measured by ELISA. Levels of the highly aggregated, FA-extractable form of $\mathrm{A} \beta$ and SDSsoluble $\mathrm{A} \beta_{1-42}$ and $\mathrm{A} \beta_{1-40}$ were reduced in the Hip. of ${ }^{* *} p<0.01,{ }^{* * *} p<0.001$.
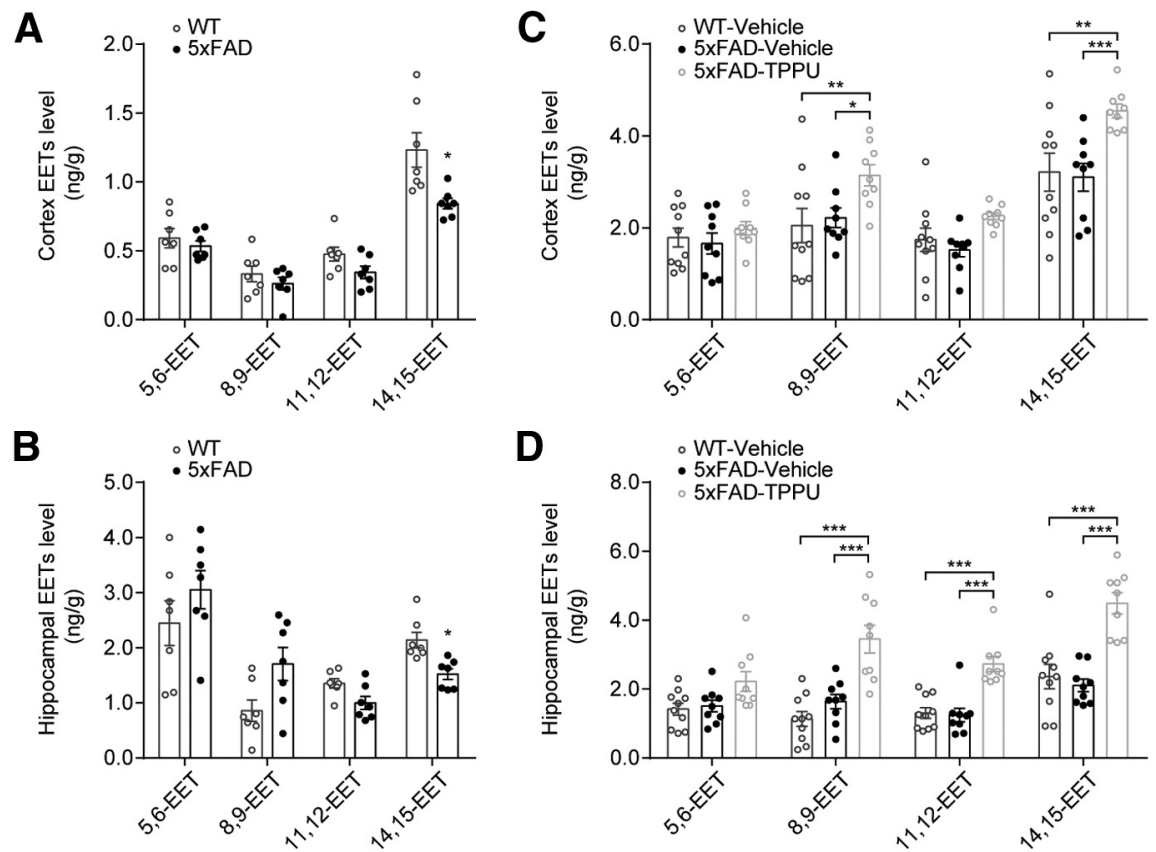

Figure 5. $\quad 14,15$-EET levels are increased in $5 \times$ FAD mice following treatment with TPPU. $\boldsymbol{A}, \boldsymbol{B}$, Relative EET levels in the cerebral cortex and hippocampus of 3-month-old male $5 \times$ FAD mice $(n=7)$. C, D, Relative EET levels in the cerebral cortices and hippocampi of 6-month-old male WT mice treated with vehicle, and $5 \times$ FAD mice treated with vehicle or TPPU (WT-vehicle, $n=10 ; 5 \times$ FAD-vehicle, $n=9 ; 5 \times$ FAD-TPPU, $n=9$ ). Data are presented as the mean \pm SEM. ${ }^{*} p<0.05$,

$5 \times$ FAD mice treated with TPPU (Fig. $3 E, F$; FA fraction: A $\beta_{1-}$ 40, $F_{(2,15)}=17.59, p<0.001 ; \mathrm{A} \beta_{1-42}, F_{(2,15)}=10.2, p=0.002$; SDS fraction: $\mathrm{A} \beta_{1-40}, F_{(2,15)}=49.82, p<0.001 ; \mathrm{A} \beta_{1-42}, F_{(2,15)}$ $=10.82, p=0.001$, one-way ANOVA); a similar effect was observed in female $5 \times \mathrm{FAD}$ mice using thioflavin $\mathrm{S}$ staining 
A

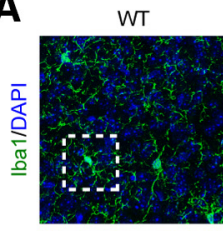

$5 \times F A D ; E p h \times 2^{+/+}$
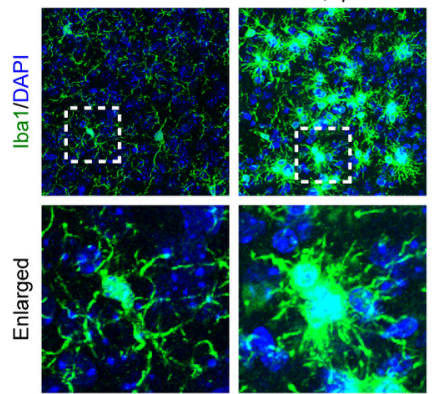

D

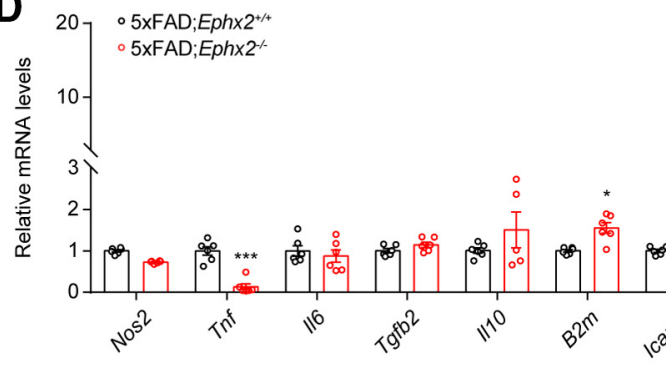

G
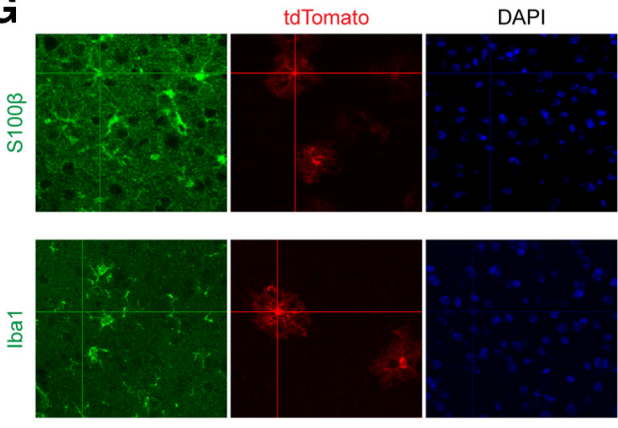

B

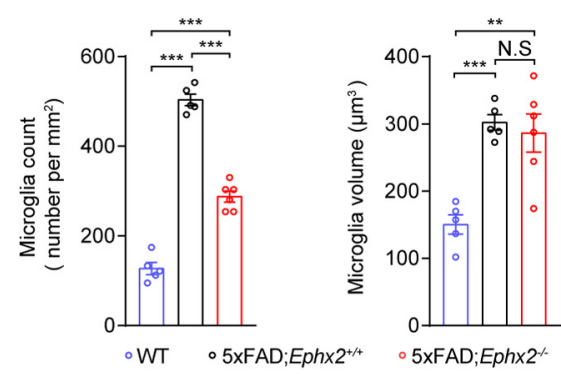

E
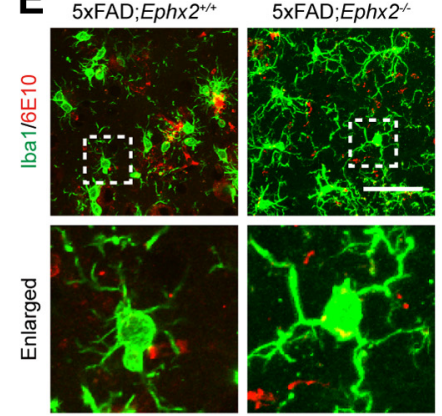

$\mathbf{F}$

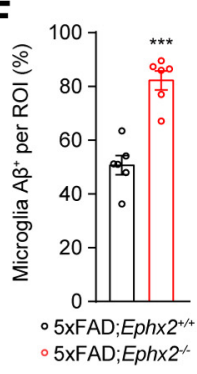

H $\quad$ Vehicle
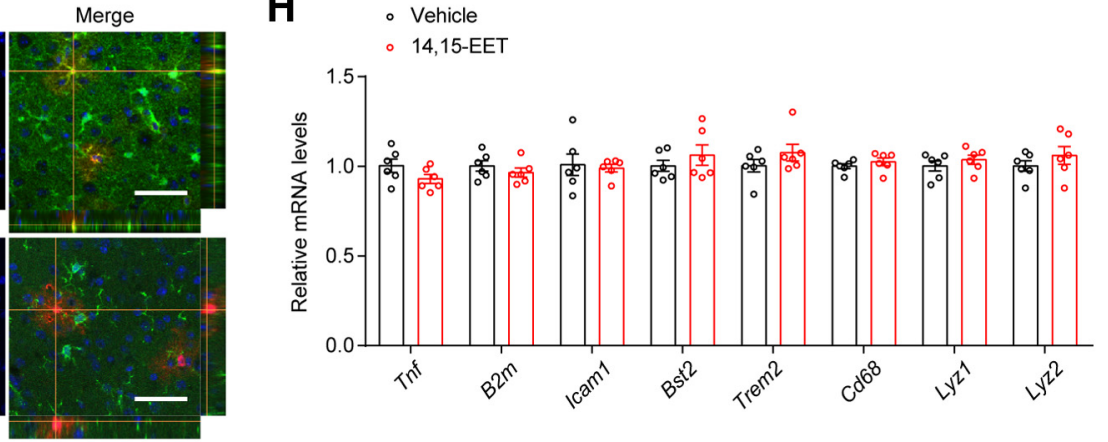

Figure 6. Deletion of Ephx2 induces an enhanced engulfment ability of microglia. $\boldsymbol{A}$, Representative images of immunohistochemistry with anti-lba1. Scale bar, $50 \mu \mathrm{m}$. $\boldsymbol{B}$, The number of Iba1-positive microglia in the motor cortex $(n=5-6)$. C, Diameters of Iba1-positive microglial cell bodies $(n=5-6)$. $\boldsymbol{D}$, The mRNA levels of genes related to microglial function, normalized to those of sex-matched control littermates $(n=5-6)$. $\boldsymbol{E}, \boldsymbol{F}$, Percentage of microglial cell bodies that are also A $\beta$-positive $(n=6)$. Scale bar, $50 \mu \mathrm{m}$. ROl, Region of interest. $\mathbf{G}$, Representative images of immunohistochemistry with anti-S100 $\beta$ or anti-lba1 in Ephx2-CreER ${ }^{\mathrm{T}}$; ROSA26-tdTomato mice following tamoxifen injection. Scale bar, $50 \mu \mathrm{m}$. $\boldsymbol{H}$, The mRNA levels of genes regulating the engulfment ability of microglia in BV2 cells following 14,15-EET $(1 \mu \mathrm{M})$ application for $3 \mathrm{~h}$, normalized to each control $(n=6)$. Data are presented as the mean \pm SEM. ${ }^{*} p<0.05$; ${ }^{* *} p<0.01 ;{ }^{* * *} p<0.001$, N.S., not significant.

(Fig. 3G; MC, $t_{(24)}=6.859, p<0.001$; Hip., $t_{(24)}=3.177$, $p=0.008$, multiple $t$ tests following Bonferroni correction). As the effect of TPPU was not sex or dose dependent, in subsequent experiments we used male mice treated with TPPU at a concentration of $1 \mathrm{mg} / \mathrm{kg}$.

We also assessed the effect of TPPU on spatial memory function in $5 \times \mathrm{FAD}$ mice with the MWM. In both the acquisition phase and probe trial, TPPU-treated $5 \times \mathrm{FAD}$ mice showed a learning ability similar to that of their vehicle-treated WT littermates, whereas vehicle-treated $5 \times \mathrm{FAD}$ mice exhibited marked impairments in spatial learning and memory (Fig. $4 A-C$; latency: $F_{(10,10,10)}=9.941, p=0.001$, repeated-measures ANOVA; percentage of time spend in quadrant: WT-vehicle, $t_{(54)}=8.76$, $p<0.001 ; 5 \times$ FAD-vehicle, $t_{(54)}=2.24, p=0.088 ; 5 \times$ FADTPPU, $t_{(54)}=6.984, p<0.001$, multiple $t$ tests following Bonferroni correction; number of target platform crossings: $F_{(2,27)}=9.21, p=0.001$, one-way ANOVA). TPPU had no effect on swimming speed or latency in the cued test (Fig. $4 D, E$; speed test, $F_{(2,27)}=0.5979, p=0.5571$; cued test, $F_{(2,27)}=0.3442$, $p=0.712$, one-way ANOVA). In the Y-maze test, the cognitive deficits of $5 \times$ FAD mice were alleviated by treatment with TPPU
(Fig. 4F,G; alternation, $F_{(2,27)}=6.359, p=0.006$; number of entries, $F_{(2,27)}=2.896, p=0.073$, one-way ANOVA), whereas locomotion was unaffected (Fig. $4 H, I$; total distances, $F_{(10,10,10)}=$ 0.287, $p=0.753$; center time, $F_{(10,10,10)}=2.444, p=0.106$, repeated-measures ANOVA). These data suggest that inhibiting sEH activity confers neuroprotection in $5 \times$ FAD mice.

EET levels are altered in the brain of AD model mice sEH is an enzyme that converts EETs to dihydroxyeicosatrienoic acids, thereby regulating EET signaling (Kodani and Hammock, 2015). To clarify the mechanisms underlying the neuroprotective effects of Ephx2 deficiency, we evaluated the brain levels of four regioisomeric EETs-namely, 5,6-EET, 8,9- EET, 11,12- EET, and 14,15-EET-by liquid chromatography-mass spectrometry (Zhang et al., 2018). In both the cortex and Hip., 14,15-EET levels were lower in 3 -month-old male $5 \times \mathrm{FAD}$ mice than in their sex-matched WT littermates (Fig. $5 A, B$; cortex: 5,6-EET, $t_{(12)}=$ $0.722, p>0.999 ; 8,9$-EET, $t_{(12)}=0.974, p>0.999 ; 11,12$-EET, $t_{(12)}=1.965, p=0.292 ; 14,15$-EET, $t_{(12)}=2.978, p=0.046$; Hip.: 5,6 -EET, $t_{(12)}=1.136, p>0.999 ; 8,9-E E T, t_{(12)}=2.361, p=0.144$; $11,12-\mathrm{EET}, t_{(12)}=2.454, p=0.121 ; 14,15-\mathrm{EET}, t_{(12)}=3.584$, 
A

GFAP

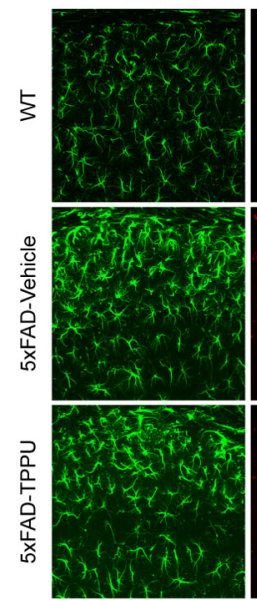

C

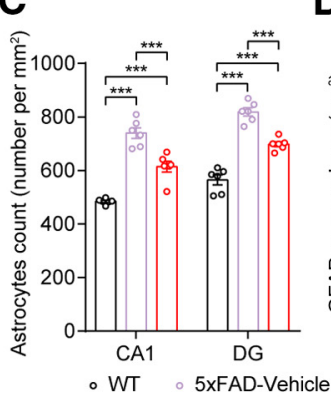

6E10

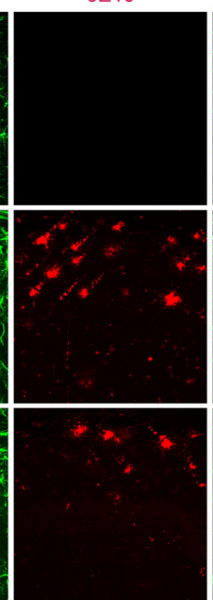

D

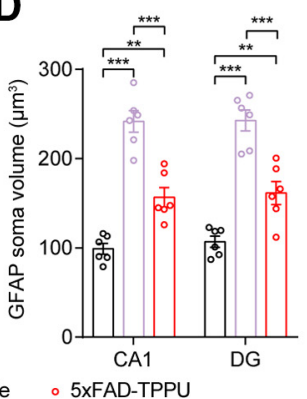

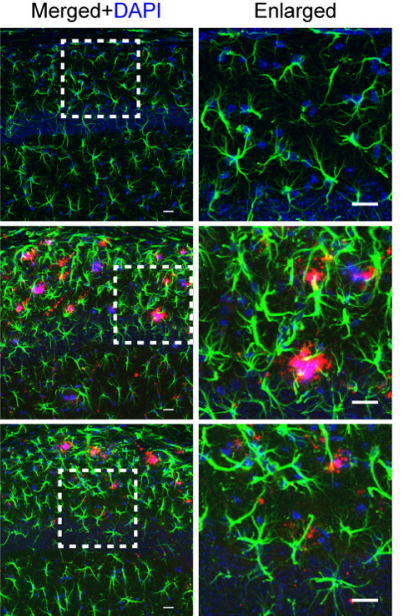

E
B GFAP

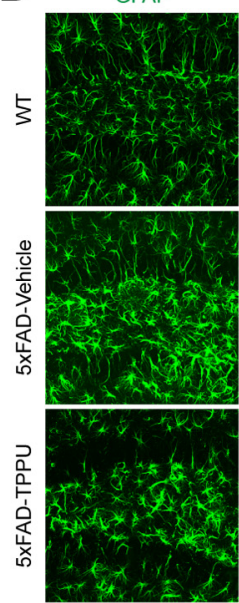

$\mathbf{F}$
6E10

G

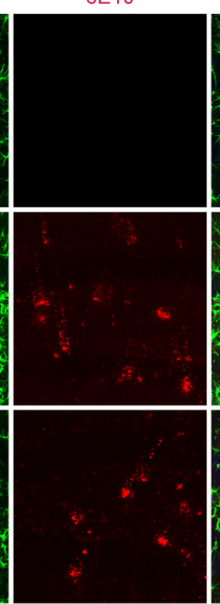

Merged+DAPI

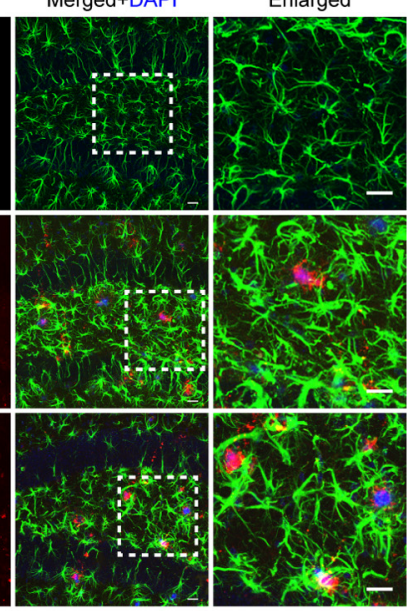

H

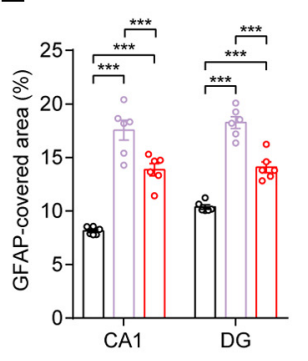

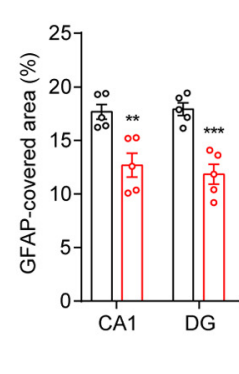

Figure 7. TPPU treatment reduces astrocyte reactivity in $5 \times F A D$ mice. $\boldsymbol{A}, \boldsymbol{B}$, Representative immunofluorescence images of GFAP and $A \beta(6 \mathrm{E} 10)$ in the $\mathrm{CA} 1(\boldsymbol{A})$ and DG $(\boldsymbol{B})$ regions of the hippocampus in 6-month-old male WT mice and $5 \times$ FAD mice treated with vehicle or TPPU. $\boldsymbol{C}-\boldsymbol{E}$, Quantitative analysis of the number, the soma volume, and the covered area of astrocytes in CA1 and DG regions of the hippocampus in 6-month-old male WT and $5 \times$ FAD mice treated with vehicle or TPPU $(n=6)$. Scale bar, $20 \mu$ m. F-H, Quantitative analysis of the number, soma volume, and the covered area of astrocytes in CA1 and DG regions of 6-month-old male $5 \times F A D ; E p h \times 2^{-1-}$ mice and WT littermates $(n=5)$. Data are presented as the mean \pm SEM. ${ }^{* *} p<0.01,{ }^{* * *} p<0.001$.

$p=0.015$, multiple $t$ tests following Bonferroni correction). In contrast, in 6-month-old $5 \times$ FAD mice, 8 ,9-EET and 14,15-EET levels in the cortex were increased by treatment with TPPU, although the brain level of 14,15 -EET was not decreased in vehicle-treated $5 \times \mathrm{FAD}$ mice compared with WT littermates (Fig. $5 C$; interaction, $F_{(6,75)}=1.721, p=0.127$, two-way ANOVA). On the other hand, hippocampal levels of all EETs except for 5,6EET were increased by TPPU treatment compared with vehicletreated littermates (Fig. $5 D$; interaction, $F_{(6,75)}=3.284, p=0.006$, two-way ANOVA). These data suggest that elevated levels of EETs-especially 14,15-EET-contribute to the neuroprotection conferred by sEH inhibition.

\section{Deletion of Ephx2 enhances the engulfment ability of microglia}

Accumulating evidence suggests that microglia play a role in AD pathology (Deczkowska et al., 2018). To evaluate the effect of Ephx2 deficiency on $\mathrm{A} \beta$-induced microglial responses in $5 \times \mathrm{FAD}$ mice, we used an antibody against microglial marker Iba-1 to label microglia in the MC sections and examined morphologic features of microglia activation. Compared with sex-matched WT littermates, the number of Iba-1-positive cells was significantly increased in male $5 \times \mathrm{FAD}$;Eph $\times 2^{+/+}$ mice, and the volume of the microglia cell body was enlarged. These results are consistent with those of a previous report (Iaccarino et al., 2016). In contrast, Ephx2 deletion induced a marked decrease in the number of microglia, without affecting the volume of microglia cell body (Fig. $6 A-C$; count, $F_{(2,13)}=$
200.7, $p<0.001$; volume, $F_{(2,13)}=15, p=0.0004$, one-way ANOVA). Using qRT-PCR, we analyzed transcriptional changes and found that the mRNA levels of TNF- $\alpha$, an inflammatory marker (Minami et al., 2014), were significantly decreased in the cerebral cortices of $5 \times \mathrm{FAD}$;Eph $\times 2^{-/-}$mice compared with those of $5 \times \mathrm{FAD} ; E p h \times 2^{+/+}$mice. Interestingly, the mRNA levels of microglial engulfment-associated genes, including B2m, Icam1, Bst2, Trem2, Cd68, Lyz1, and Lyz2 were increased (Fig. $6 D$; Nos2, $t_{(49)}=1.371, p=0.883$; Tnf, $t_{(49)}=4.385, p<0.001 ;$ Il6, $t_{(49)}=0.612, p>0.999 ; \mathrm{Tgfb} 2$, $t_{(49)}=0.722, p>0.999 ;$ Il10, $t_{(49)}=2.409, p=0.099 ; B 2 m, t_{(70)}=$ $2.955, p=0.030 ;$ Icam $1, t_{(70)}=3.865, p=0.002 ;$ Trem $2, t_{(70)}=$ 5.472, $p<0.001 ; C d 33, t_{(70)}=1.544, p=0.890 ;$ Fth 1 , $t_{(70)}=0.080, p>0.999 ;$ Tmem119, $t_{(70)}=0.202, p>0.999 ;$ Cd68, $t_{(29)}=3.614, p=0.003 ;$ Lyz1, $t_{(29)}=7.037, p<0.001$; Lyz2, $t_{(29)}=8.287, p<0.001$, multiple $t$ tests following Bonferroni correction). Moreover, the percentage of microglia colocalized with $\mathrm{A} \beta$ in the cell body increased $>30 \%$ in the MC of $5 \times \mathrm{FAD}$;Eph $\times 2^{-1-}$ mice compared with that of $5 \times \mathrm{FAD} ; E p h \times 2^{+/+}$mice (Fig. $6 E, F ; t_{(10)}=6.275, p<0.001$, unpaired $t$ test). However, we found that $s E H$ is mainly expressed on astrocytes ( $100 \beta$-positive cells), not microglia (Fig. 6G). To detect whether 14,15-EET acts directly on microglia, BV2 cells, a mouse microglial cell line, were treated with 14,15-EET $(1 \mu \mathrm{M})$ for $3 \mathrm{~h}$. qRT-PCR analysis showed that 14,15-EET application had little effect on the mRNA levels of genes, which were upregulated by Ephx2 deletion (Fig. $6 H$; Tnf, $t_{(80)}=1.456, p>0.999 ; B 2 m, t_{(80)}=$ 
A
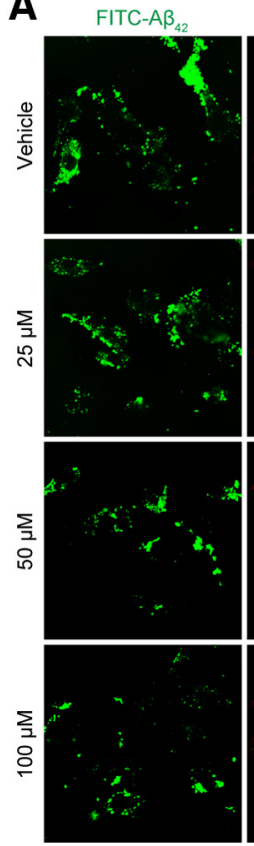
LysoTracker
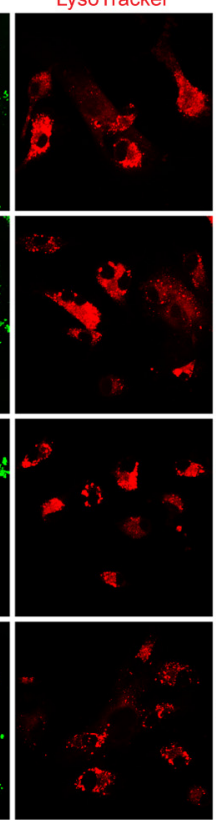

D
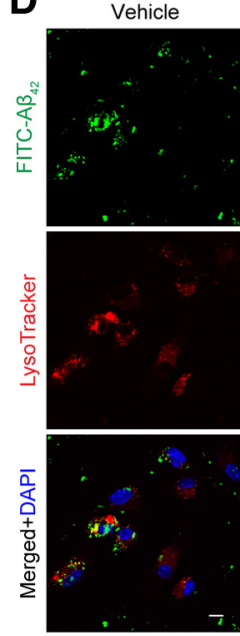

5,6-EET

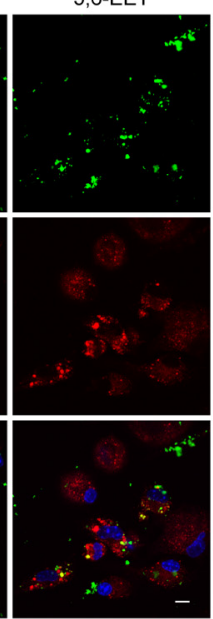

Merged+DAPI
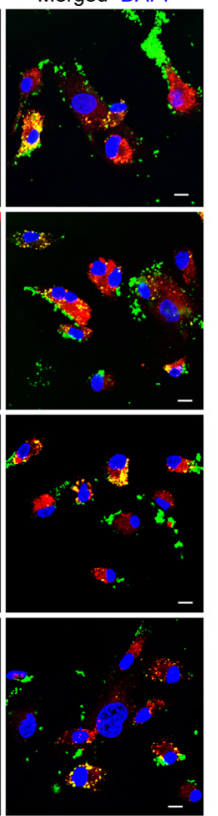

8,9-EET

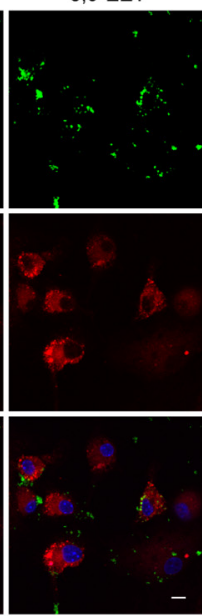

B
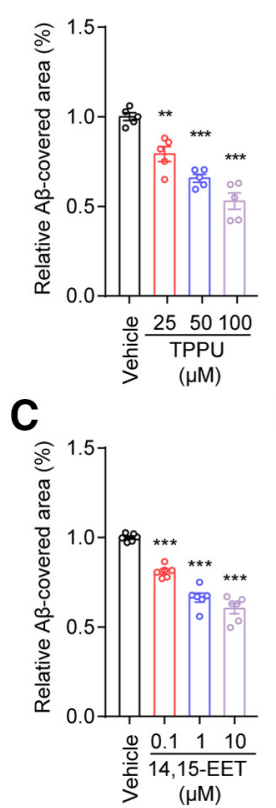

$\mathbf{F}$

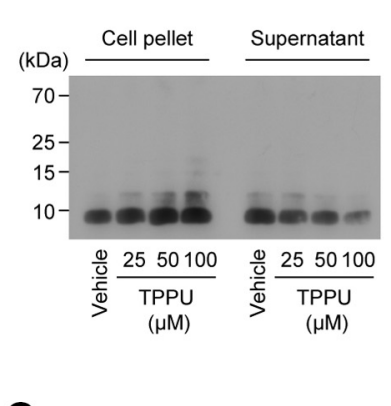

G

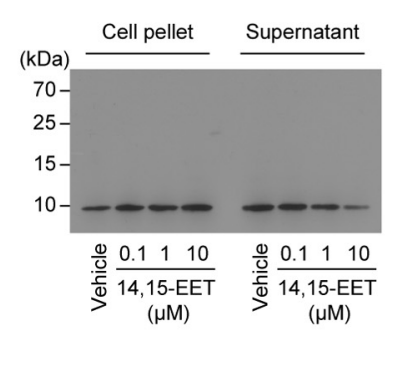

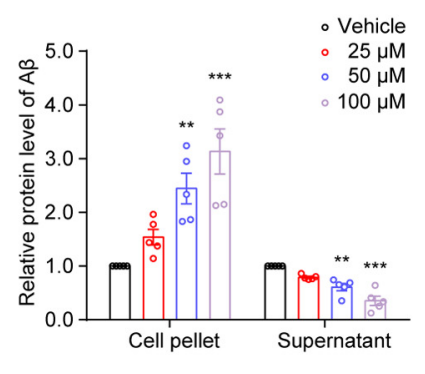

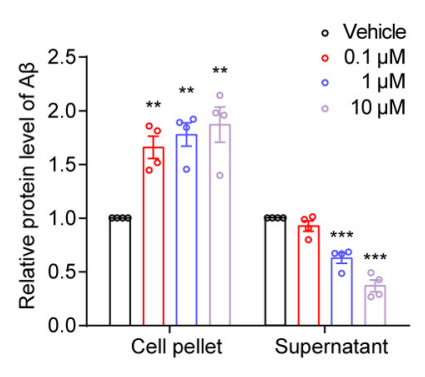

Figure 8. TPPU or 14,15-EET application promotes $A \beta$ clearance in primary cultured adult mouse astrocytes. $\boldsymbol{A}$, Representative immunofluorescence images of TPPU-induced $A \beta$ uptake in primary astrocyte cultures derived from the cerebral cortex of adult $(57 \mathrm{BL} / 6 \mathrm{~J}$ mice $(n=5)$. Scale bar, $10 \mu \mathrm{m}$. $\boldsymbol{B}, \boldsymbol{C}$, TPPU $(\boldsymbol{B})$ and 14,15 -EET $(\boldsymbol{C})$ promote $A \beta$ uptake in primary astrocyte cultures $(n=5)$. $\boldsymbol{D}, \boldsymbol{E}$, Effects of the other EETs on astrocyte $A \beta$ clearance in primary cultures of adult astrocytes $(n=2$, repeated three times). Scale bar, $10 \mu$ m. $\boldsymbol{F}, \boldsymbol{G}$, Western blot analysis of $\mathrm{A} \beta$ protein levels in the cell pellet and culture medium $1 \mathrm{~h}$ after application of TPPU $(\boldsymbol{F})$ or 14,15-EET $(\boldsymbol{G} ; n=5)$. $\boldsymbol{H}$, Western blot analysis of $A \beta$ protein levels in the cell pellet and culture medium following treatment with the other EETs $\left(n=2\right.$, repeated two times). Data are presented as the mean \pm SEM. ${ }^{* *} p<0.01,{ }^{* * *} p<0.001$.

$0.726, p>0.999 ; \operatorname{Icam} 1, t_{(80)}=0.368, p>0.999 ; B s t 2, t_{(80)}=$ $1.188, p>0.999 ;$ Trem $2, t_{(80)}=1.447, p>0.999 ;$ Cd68, $t_{(80)}=0.488, p>0.999 ; L y z 1, t_{(80)}=0.681, p>0.999 ; L y z 2$, $t_{(80)}=1.154, p>0.999$, multiple $t$ tests following Bonferroni correction). Together, these results indicate that deletion of Ephx2 promotes the phagocytic ability of microglia through an indirect pathway.

\section{4,15-EET facilitates astrocytic $A \beta$ clearance}

Reactive astrogliosis is another feature of $\mathrm{AD}$. We recently showed that $\mathrm{sEH}$ is localized mainly in the lysosome of astrocytes, which are the presumed target cells for 14,15-EET in the brain (Qin et al., 2019; Xiong et al., 2019). We therefore examined the morphology of astrocytes and their interactions with $\mathrm{A} \beta$. Immunolabeling of the astrocyte marker GFAP revealed greater numbers and larger areas of GFAP-positive astrocytes with enlarged soma in the CA1 region and DG of vehicletreated 6-month-old male $5 \times$ FAD mice compared with WT littermates, similar to a previous report (Wu et al., 2014). In contrast, TPPU-treated $5 \times$ FAD mice had fewer reactive astrocytes in the CA1 area and DG, as evidenced by the decreased soma volume, the density of GFAP-positive cells, and the smaller area of GFAP immunoreactivity compared with vehicle-treated mice (Fig. 7A-E; interaction: count, $F_{(2,15)}=0.011, p=0.989$; soma volume, $F_{(2,15)}=0.044, p=0.958$; GFAP-covered area, $F_{(2,15)}=1.469, p=0.262$, two-way ANOVA). Similar effects were observed following Ephx2 deletion in $5 \times \mathrm{FAD}$ mice (Fig. $7 F-H$; interaction: count, $F_{(1,8)}=0.020, p=0.890$; soma volume, $F_{(1,8)}=0.022, p=0.885$; GFAP-covered area, $F_{(1,8)}=1.058$, $p=0.334$, two-way ANOVA). These results indicate that $\mathrm{sEH}$ inhibition or Ephx2 deletion reduces astrocyte reactivation in $5 \times$ FAD mice. 

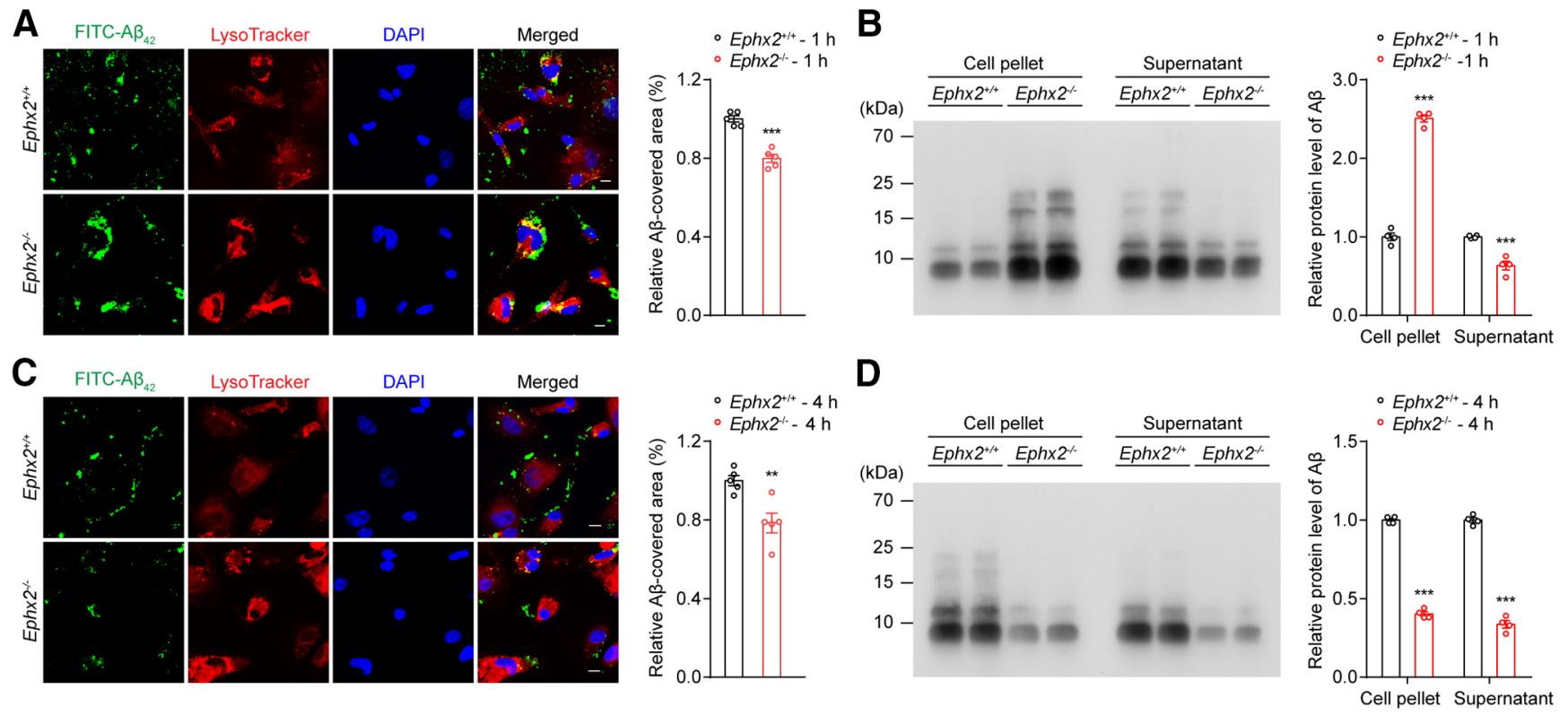

Figure 9. Deletion of Ephx2 promotes $A \beta$ clearance in primary cultured adult mouse astrocytes. $A$, Representative immunofluorescence images and quantification of $A \beta$ uptake in primary astrocyte cultures derived from the cerebral cortex of adult $E p h x 2^{-1-}$ mice and control littermates, $1 \mathrm{~h}$ after incubated astrocytes with fluorescein isothiocyanate-conjugated $A \beta_{1-42}(n=5)$. Scale bar, $10 \mu \mathrm{m}$. B. Western blot analysis of $A \beta$ protein levels in the cell pellet and culture medium ( $n=2$, repeated two times). $C$, Representative immunofluorescence images and quantifi-

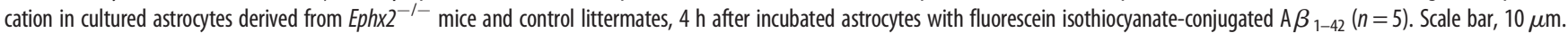
$D$, Western blot analysis of $A \beta$ protein levels in the cell pellet and culture medium $4 \mathrm{~h}$ after incubation of astrocytes with fluorescein isothiocyanate-conjugated $A \beta{ }_{1-42}(n=2$, repeated two times). Data are presented as the mean \pm SEM. ${ }^{* *} p<0.01,{ }^{* *} p<0.001$.

We next examined whether 14,15-EET enhances astrocytemediated $\mathrm{A} \beta$ clearance in vitro. To this end, primary cultures of astrocytes from adult C57BL/6J mice were incubated with fluorescein isothiocyanate-conjugated $\mathrm{A} \beta_{1-42}$. A $1 \mathrm{~h}$ application of TPPU or 14,15-EET, but not 5,6-EET, 8,9-EET, or 11,12-EET, decreased the area covered by $\mathrm{A} \beta$ in a dose-dependent manner compared with vehicle treatment (Fig. 8A-E; TPPU, $F_{(3,16)}=$ 33.94, $p<0.001 ; 14,15$-EET, $F_{(3,20)}=73.18, p<0.001$; other EETs, $F_{(3,20)}=1.290, p=0.305$, one-way ANOVA). These results were supported by Western blot analysis showing that the total amount of $\mathrm{A} \beta$ was higher in the cell pellet of cultured astrocytes but lower in the culture medium following treatment with TPPU or 14,15-EET compared with vehicle (Fig. 8F,G; TPPU: cell pellet, $F_{(3,16)}=12.890, p<0.001$; supernatant, $F_{(3,16)}=24.290$, $p<0.001 ; 14,15$-EET: cell pellet, $F_{(3,12)}=12.680, p=0.001$; supernatant, $F_{(3,12)}=44.64, p<0.001$, one-way ANOVA). As expected, 5,6-EET, 8,9-EET, and 11,12-EET treatment had no effect on $\mathrm{A} \beta$ clearance (Fig. $8 \mathrm{H}$; other EETs: cell pellet, $F_{(3,12)}=$ $0.274, p=0.843$; supernatant, $F_{(3,12)}=0.369, p=0.777$, one-way ANOVA). Because higher intracellular and lower extracellular $\mathrm{A} \beta$ levels could be because of increased $\mathrm{A} \beta$ uptake but reduced degradation, and because the drug effect cannot be stable for a longer time, we observed dynamic changes of $\mathrm{A} \beta$ accumulations in cultured astrocytes derived from adult $E p h x 2^{-1-}$ mice and control littermates. Consistent with the results of TPPU and 14,15-EET applications, $1 \mathrm{~h}$ after incubation with fluorescein isothiocyanate-conjugated $\mathrm{A} \beta_{1-42}$, the area covered by $\mathrm{A} \beta$ was decreased in astrocytes derived from $E p h x 2^{-1-}$ mice compared with that of control astrocytes (Fig. $9 A ; t_{(8)}=7.76, p<0.001$, unpaired $t$ test). Meanwhile, the total amount of $\mathrm{A} \beta$ was higher in the cell pellet of cultured $E p h \times 2^{-/-}$astrocytes, but lower in the culture medium (Fig. 9B; cell pellet, $t_{(12)}=24.93, p<0.001$; supernatant, $t_{(12)}=6.046, p<0.001$, multiple $t$ tests following Bonferroni correction). Interestingly, $4 \mathrm{~h}$ after incubation with fluorescein isothiocyanate-conjugated $\mathrm{A} \beta_{1-42}$, the area covered by $\mathrm{A} \beta$ was decreased in astrocytes derived from $E p h \times 2^{-1-}$ mice (Fig. $9 C ; t_{(8)}=3.811, p=0.005$, unpaired $t$ test). We also observed that the total amount of $\mathrm{A} \beta$ in both the cell pellet and culture

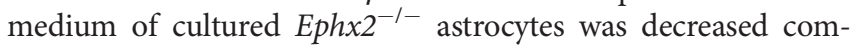
pared with controls (Fig. 9D; cell pellet, $t_{(12)}=25.08, p<0.001$; supernatant, $t_{(12)}=27.88, p<0.001$, multiple $t$ tests following Bonferroni correction). These data indicate that enhanced EET signaling promotes astrocytic $\mathrm{A} \beta$ clearance.

\section{4,15-EET enhances lysosome biogenesis in astrocytes}

Astrocytes take up $\mathrm{A} \beta$ for lysosomal degradation (De Strooper and Karran, 2016). TFEB is a master regulator of lysosome biogenesis (Sardiello et al., 2009; Xu and Ren, 2015); enhancing this process in astrocytes by TFEB overexpression was shown to promote $\mathrm{A} \beta$ uptake and to alleviate $\mathrm{AD}$ pathology (Xiao et al., 2014; Martini-Stoica et al., 2018). We therefore examined whether EET signaling modulates lysosome biogenesis. Confocal imaging revealed that TFEB was predominantly localized in the cytoplasm of astrocytes under basal culture conditions. However, the intensity of TFEB fluorescence in the nucleus of cultured astrocytes was markedly increased $15 \mathrm{~min}$ after the application of 14,15-EET (Fig. 10A; $F_{(5,30)}=27.13, p<0.001$, one-way ANOVA). This effect was also observed $5 \mathrm{~min}$ after the application of TPPU (Fig. 10B; $F_{(5,42)}=54.66, p<0.001$, one-way ANOVA), indicating that EET signaling modulates TFEB activation. These results were further verified by Western blotting showing that the level of lysosomal-associated membrane protein Lamp1 (encoded by the TFEB target gene Lamp1) was increased in 14,15-EET-treated astrocytes compared with controls (Fig. $10 C ; t_{(10)}=9.229, p<0.001$, unpaired $t$ test).

Mcoln1 is a downstream gene of TFEB encoding transient receptor potential mucolipin 1 (TRPML1), the main $\mathrm{Ca}^{2+}$ release channel in lysosomes ( $\mathrm{Xu}$ and Ren, 2015). We found that 
A

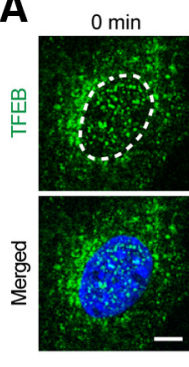

C

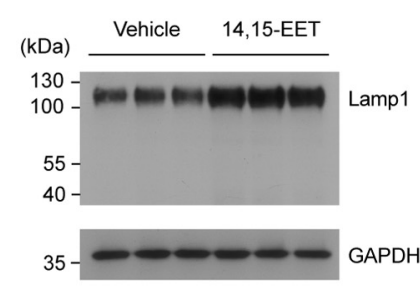

F

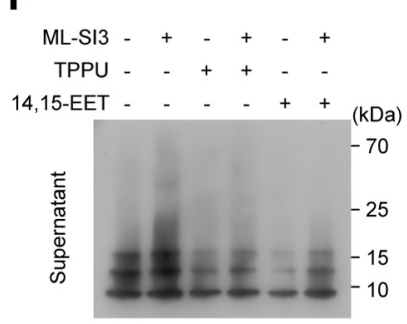

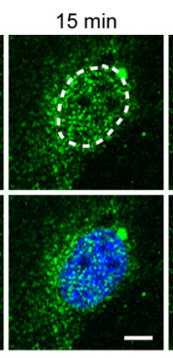
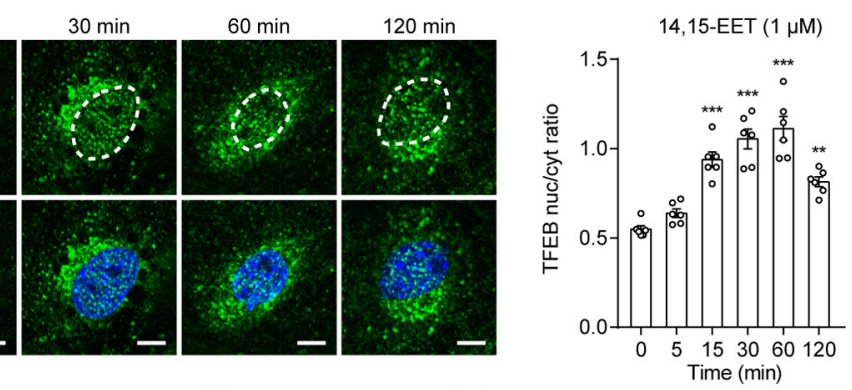

D
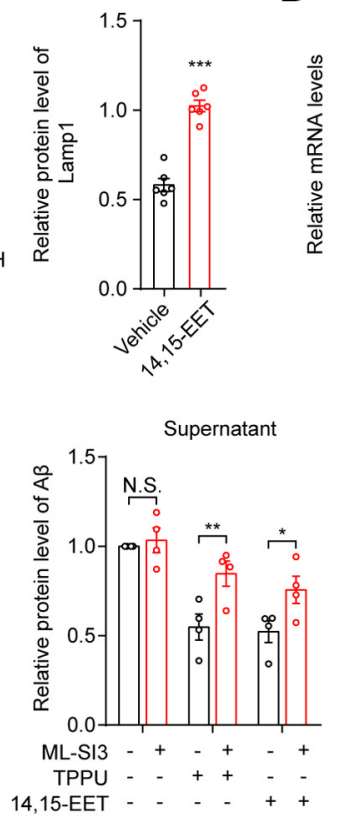

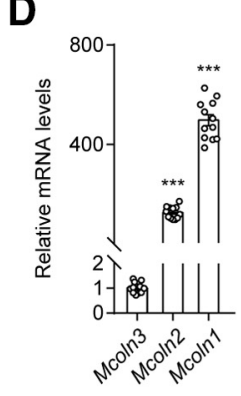

E

G

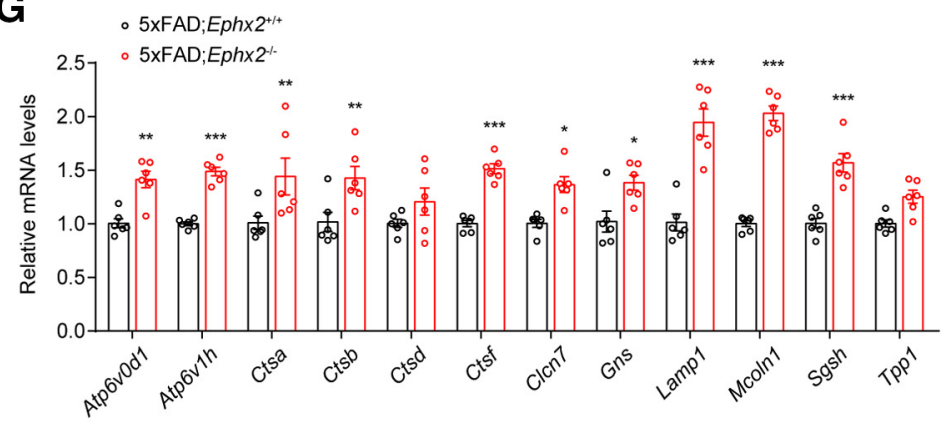

Figure 10. 14,15-EET application promotes astrocyte $A \beta$ clearance by stimulating lysosomal biogenesis. $\boldsymbol{A}$, Immunofluorescence analysis of TFEB nuclear translocation (green) and quantitative analysis of the ratio of the intensity of fluorescence in nuclear versus that in cytosol in cultured astrocytes following treatment with 14,15 -EET ( $1 \mu \mathrm{m}$ ) at the times indicated ( $n=2$, repeated three times; $\sim 900$ cells counted in each group). Scale bar, $10 \mu \mathrm{m}$. B, Quantitative analysis of the ratio of the intensity of fluorescence in nuclear/cytosol in cultured astrocytes following treatment with TPPU (100 $\mu \mathrm{m})$ at indicated times $(n=2$, repeated four times, $\sim 1000$ cells counted in each group). $C$, Western blot analysis of Lamp1 protein levels in astrocytes 15 min after treatment with 14,15-EET ( $n=3$, repeated twice). $\boldsymbol{D}$, TRPML mRNA levels in primary astrocyte cultures derived from the cerebral cortex of adult $\mathbf{C} 57 \mathrm{BL} / 6 \mathrm{~J}$ mice $(n=12)$. $\boldsymbol{E}, \boldsymbol{F}$, Western blot analysis of $A \beta$ protein levels in the cell pellet $(\boldsymbol{E})$ and culture medium $(\boldsymbol{F}) 1 \mathrm{~h}$ after TPPU (100 $\mu \mathrm{m})$ or 14,15-EET (1 $\mu \mathrm{m})$ application, with or without ML-SI3 pretreatment ( $25 \mu \mathrm{m}, 10$ min; $n=5$ ). $\mathbf{G}$, The mRNA levels of TFEB target genes in the cerebral cortex of 6 -month-old male $5 \times F A D ; E p h \times 2^{-1-}$ mice and control littermates (normalized to control littermates, $\left.n=6\right)$. Data are presented as the mean \pm SEM. ${ }^{*} p<0.05,{ }^{* *} p<0.01,{ }^{* * *} p<0.001$, N.S., not significant.

TRPML1 was the most highly expressed among TRPML channels (TRPML1-3) in cultured adult astrocytes (Fig. 10D; $F_{(2,33)}=$ $358.4, p<0.001$, one-way ANOVA). To determine whether the 14,15 -EET-induced enhancement of $\mathrm{A} \beta$ clearance in astrocytes requires TRPML1 activation, we used the synthetic TRPML1 inhibitor ML-SI3 (Zhang et al., 2016). Western blot analysis revealed that the effect of TPPU or 14,15-EET on astrocytic A $\beta$ clearance was attenuated by preincubation with ML-SI3, although ML-SI3 alone had no effect on A $\beta$ clearance (Fig. 10E, $F$; interaction: cell pellet, $F_{(2,18)}=31.340, p<0.001$; supernatant, $F_{(2,18)}=2.349, p=0.124$, two-way ANOVA). To validate whether Ephx2 deletion induces TFEB nuclear translocation in vivo, we examined the mRNA levels of TFEB target genes, including Atp6v0d1, Atp6v1h, Ctsa, Ctsb, Ctsd, Ctsf, Clcn7, Gns, Lamp1, Mcoln1, Sgsh, and Tpp1, which have previously been shown to regulate TFEB nuclear translocation (Sardiello et al., 2009; Settembre et al., 2011). qRT-PCR analysis revealed that the mRNA levels of all these genes were increased in the cerebral cortices of 6-month-old male $5 \times \mathrm{FAD}$;Eph $\times 2^{-1-}$ mice compared with those of control littermates, although the mRNA level of Tpp1 was not significantly different (Fig. 10G; Atp6v0d1, $t_{(120)}=$
3.714, $p=0.004 ;$ Atp6v1h, $t_{(120)}=4.414, p<0.001 ;$ Ctsa, $t_{(120)}=$ 3.921, $p=0.002$; Ctsb, $t_{(120)}=3.703, p=0.004 ; C t s d, t_{(120)}=1.836$, $p=0.825 ;$ Ctsf, $t_{(120)}=4.637, p<0.001 ; C l c n 7, t_{(120)}=3.280, p=$ $0.016 ;$ Gns, $t_{(120)}=3.295, p=0.016$; Lamp1, $t_{(120)}=8.455$, $p<0.001 ;$ Mcoln $1, t_{(120)}=9.321, p<0.001 ; S g s h, t_{(120)}=5.113$, $p<0.001 ; T p p 1, t_{(120)}=2.258, p=0.309$, multiple $t$ tests following Bonferroni correction). Together, these data suggest that the enhancement of $\mathrm{A} \beta$ clearance in astrocytes through EET signaling depends on increased lysosome biogenesis.

\section{4,15-EET reverses brain $\mathrm{A} \boldsymbol{\beta}$ deposition in $\mathrm{AD}$ model mice}

In $5 \times \mathrm{FAD}$ mice, brain levels of $\mathrm{A} \beta_{1-42}$ and $\mathrm{A} \beta_{1-40}$ increase dramatically starting at 2 months of age, with $\mathrm{A} \beta$ plaques appearing at $\sim 3$ months (Oakley et al., 2006). We observed, using thioflavin $\mathrm{S}$ staining, that $\mathrm{A} \beta$ deposition in male $5 \times \mathrm{FAD}$ mice occurred as early as postnatal day 78 (P78), with more $\mathrm{A} \beta$ plaques detected in the entorhinal cortex (EC), the first brain area to deteriorate in $\mathrm{AD}$ (Reagh et al., 2018; Fig. 11A). To determine whether 14,15-EET can prevent brain $\mathrm{A} \beta$ deposition in $5 \times \mathrm{FAD}$ mice, we infused 14,15 -EET $(100 \mathrm{ng} / \mathrm{ml})$ unilaterally into the Hip. of male $5 \times$ FAD mice at P75 and killed the mice 7 later (at 
P82; Fig. $11 B, C)$. A $\beta$ plaques were observed throughout the brains of vehicle-infused $5 \times$ FAD mice by thioflavin $S$ staining, whereas fewer plaques were present in the brains of mice treated with 14,15-EET (Fig. 11D; interaction, $F_{(6,40)}=$ $56.140, p<0.001$, two-way ANOVA). To test whether 14,15-EET infusion could restore normal A $\beta$ processing, we infused 14,15-EET unilaterally into the Hip. of 6-month-old male $5 \times$ FAD mice (P180). Although a $7 \mathrm{~d}$ infusion of $14,15-$ EET at a concentration of $100 \mathrm{ng} / \mathrm{ml}$ had little effect on $\mathrm{A} \beta$ deposition in the brain, the number of $\mathrm{A} \beta$ plaques in whole brain sections-including bilateral MC, Hip., and $\mathrm{EC}$-was significantly reduced after a $7 \mathrm{~d}$ infusion of a higher concentration of 14,15-EET (200 ng/ml) compared with vehicle-treated control littermates (Fig. 12; interaction: 14,15-EET $100 \mathrm{ng} / \mathrm{ml}, F_{(6,64)}=0.199$, $p=0.976 ; 14,15$-EET $200 \mathrm{ng} / \mathrm{ml}, F_{(6,40)}=$ $12.520, \quad p<0.001$, two-way ANOVA). These data demonstrate that 14,15-EET reverses $\mathrm{A} \beta$ deposition in the brain.

\section{Discussion}

The pathophysiology of $\mathrm{AD}$ is complex, involving $\mathrm{A} \beta$ plaques, phosphorylated tau tangles, synaptic degeneration, cognitive impairment, and abnormalities in lipid metabolism as well as neurovascular coupling. Although the amyloid cascade hypothesis remains controversial, it is widely acknowledged that $\mathrm{A} \beta$ accumulation or plaque formation is neurotoxic and can induce $\mathrm{AD}$. The results of the present study indicate that inhibiting $\mathrm{sEH}$ activity or deleting the Ephx2 gene reduces brain $\mathrm{A} \beta$ deposition and mitigates $\mathrm{AD}$-associated pathology, including cognitive deficits, in AD model mice. Moreover, sEH inhibition increased brain levels of 14,15-EET, which can promote astrocyte $\mathrm{A} \beta$ clearance by enhancing lysosomal biogenesis. Most importantly, we showed that the direct infusion of 14,15-EET to the Hip. not only prevented the aggregation of $\mathrm{A} \beta$ but also reversed $\mathrm{A} \beta$ deposits in 6 -month-old $5 \times$ FAD mice. These results demonstrate that EET signaling is involved in astrocyte $\mathrm{A} \beta$ clearance and that therapeutic strategies targeting this pathway may be a treatment option for AD.

Cytochrome P450 enzymes in the eicosanoid pathway have the following two distinct enzymatic activities: $\omega$-hydroxylases generate hydroxyeicosatetraenoic acids, while epoxygenases convert ARA into EETs. sEH modulates EET signaling in many tissues by adding a water molecule across the epoxide moiety of EETs to produce less active dihydroxyeicosatrienoic acids. 14,15EET is the preferred substrate for sEH (Imig, 2012). In the present study, sEH inhibition increased brain levels of EETs, especially 14,15-EET; on the other hand, 14,15-EET levels were reduced in 3 -month-old, but not 6 -month-old, $5 \times$ FAD mice. The higher EET levels in the latter could be because EETs from the peripheral circulation accumulate in the brain with aging or under pathophysiologic conditions (Qin et al., 2019). In the adult
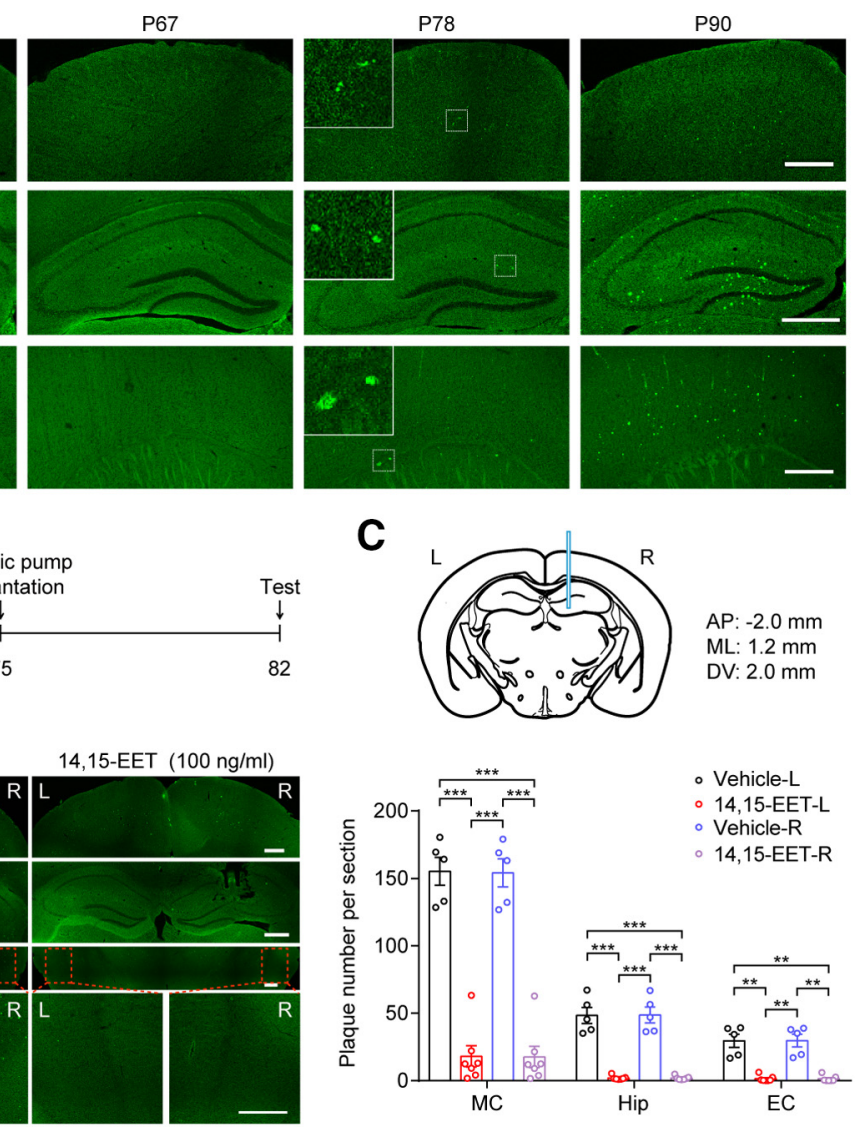

Figure 11. 14,15-EET infusion prevents brain $A \beta$ deposition in $5 \times F A D$ mice. $\boldsymbol{A}$, Representative images of thioflavin $\boldsymbol{S}$ ing in the MC, Hip., and EC of male $5 \times$ FAD mice killed at P30, P67, P78, and P90 ( $n=3 /$ group at each time point). $\boldsymbol{B}$, , Experimental design for the infusion of 14,15-EET using an osmotic pump implanted in the right Hip. The light blue verti, line in $\mathbf{C}$ shows the location of the pump, with brain coordinates shown to the right of the schematic. L, Left; $R$, right. $\boldsymbol{D}$, 14,15 -EET $(100 \mathrm{ng} / \mathrm{ml})$ infusion prevented $A \beta$ deposition in the brains of $5 \times$ FAD mice (vehicle, $n=5 ; 14,15$-EET, $n=7$ ). Scale bar, $500 \mu \mathrm{m}$. Data are presented as the mean \pm SEM. ${ }^{*} p<0.05,{ }^{* *} p<0.01,{ }^{* * *} p<0.001$.

brain, $\mathrm{sEH}$ is mainly expressed in astrocytes and requires oligomerization for its activity (Qin et al., 2019; Xiong et al., 2019). Therefore, it is worth examining postmortem brain samples of $\mathrm{AD}$ patients to determine whether $\mathrm{sEH}$ oligomer levels are increased.

Studies showed that 14,15 -EET can inhibit microglial activation in response to brain injury (Liu et al., 2016; Wu et al., 2017). We found that the deletion of Ephx2 increased the brain levels of EETs, especially 14,15-EET (Qin et al., 2019), and modulated microglial reactions. Moreover, we found that the mRNA levels of microglial engulfment associated genes, including $B 2 \mathrm{~m}$, Icam1, Bst2, Trem2, Cd68, Lyz1, and Lyz2, were upregulated in the brains of $5 \times \mathrm{FAD}$;Eph $\times 2^{-1-}$ mice compared with control littermates. These data suggest that 14,15 -EET can promote the ability of microglia to uptake cerebral $\mathrm{A} \beta$. However, we found that $\mathrm{sEH}$ is not expressed on microglia, and 14,15-EET application had no effect on the mRNA levels of genes regulating the engulfment ability of microglia in BV2 cells. Previous studies have shown that 14,15 -EET promotes neurotrophic production by astrocytes, such as brain-derived neurotrophic factor, which modulates microglial activation (Mizoguchi et al., 2014; Yuan et al., 2016). Therefore, the deletion of Ephx2 may modulate microglial reaction through an indirect pathway. It will be of particular interest to know which (and how) molecules derived from astrocytes following increased 14,15-EET mediate the microglial reaction. 
A

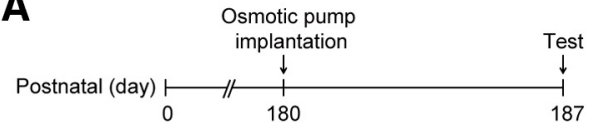

C
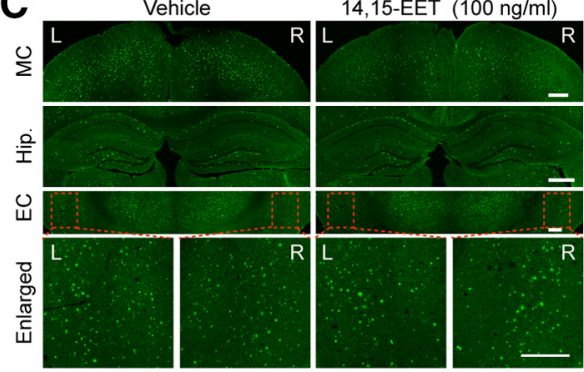

D

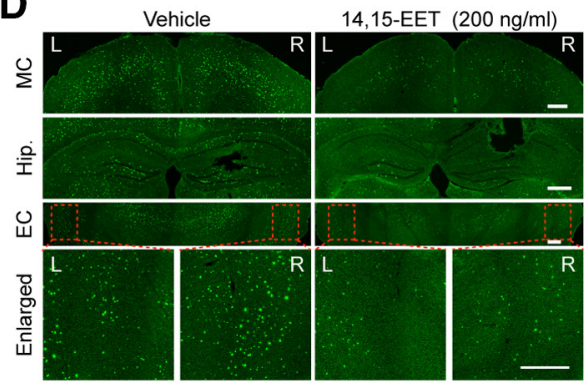

B
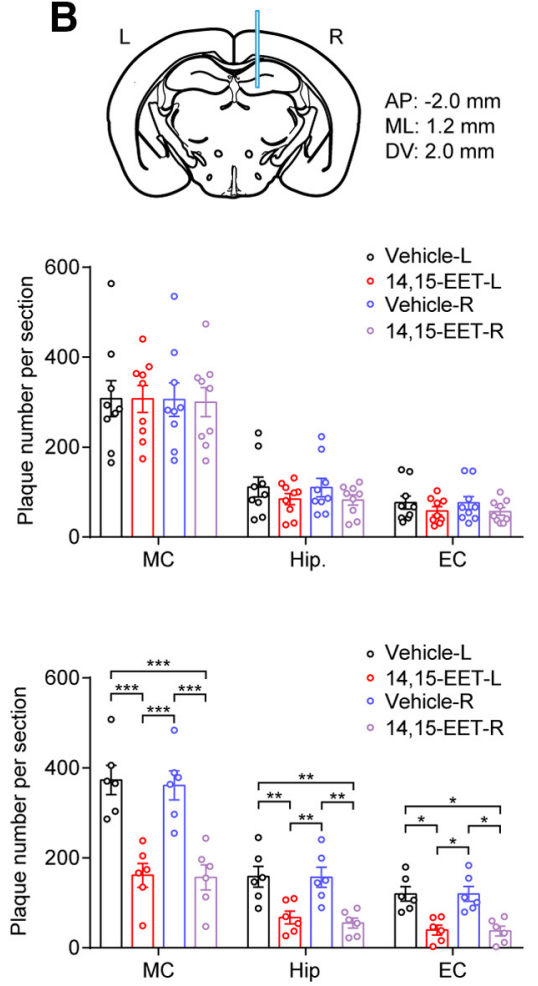

Figure 12. Hippocampal infusion of 14,15 -EET reverses brain $A \beta$ deposition in 6-month-old $5 \times F A D$ mice. $\boldsymbol{A}, \boldsymbol{B}$, Experimental design for the hippocampal infusion of 14,15-EET using an osmotic pump. The light blue vertical line in $\boldsymbol{B}$ shows the location of the pump, with brain coordinates shown to the right of the schematic. L, Left; $R$, right. C, Lower concentration of 14,15-EET $(100 \mathrm{ng} / \mathrm{ml})$ infusion had no effect on $A \beta$ degradation in the brains of 6 -month-old $5 \times$ FAD mice $(n=9)$. $\boldsymbol{D}, \mathrm{A}$ higher concentration of 14,15 -EET $(200 \mathrm{ng} / \mathrm{ml})$ infusion enhanced $A \beta$ degradation in the brains of 6 -month-old $5 \times$ FAD mice $(n=6)$. Scale bar, $500 \mu \mathrm{m}$. Data are presented as the mean \pm SEM. ${ }^{*} p<0.05,{ }^{* *} p<0.01,{ }^{* * *} p<0.001$.

Astrocytes are the most abundant cell type in the brain and take up $\mathrm{A} \beta$ for lysosomal degradation, while the underlying mechanism is not well understood. Enhancing lysosomal biogenesis in astrocytes by expressing exogenous TFEB promotes $\mathrm{A} \beta$ uptake and alleviates AD pathology (Xiao et al., 2014; MartiniStoica et al., 2018). In this study, we provide evidence for a link between EET signaling and lysosomal biogenesis in astrocytes. The application of TPPU and 14,15-EET induced TFEB nuclear translocation. These results were verified by examining the mRNA levels of TFEB-targeted genes, showing all selected genes that regulate TFEB nuclear translocation to be unregulated in the cerebral cortices of 6-month-old $5 \times \mathrm{FAD} ; E p h \times 2^{-1-}$ mice compared with those of control littermates. These data indicate that EET signaling modulates TFEB transcriptional activity. Second, TRPML1, which regulates most lysosomal trafficking (Xu and Ren, 2015), is a transcriptional target of TFEB (Medina et al., 2011). We found that TRPML1 blockade attenuated the stimulatory effect of 14,15-EET and TPPU on astrocyte $\mathrm{A} \beta$ clearance induced by increased EET signaling, suggesting that TRPML1 activation is required for this process. Genome-wide association studies have shown that perturbed lipoprotein metabolism is associated with an elevated risk of $\mathrm{AD}$; additionally, abnormal sphingolipid metabolism in the brain was identified as part of the pathogenesis of $\mathrm{AD}$, showing increased sphingomyelinase activity and decreased sphingomyelins levels in the brain of patients with $\mathrm{AD}$ (Karch and Goate, 2015; Crivelli et al., 2020). Together with a previous report showing that TRPML1 activity is suppressed by sphingomyelin but potentiated by sphingomyelinase (Shen et al., 2012), these results imply that
TRPML1 activation plays an essential role in regulating $\mathrm{A} \beta$ clearance in astrocytes.

Brain astrocytes are extremely heterogeneous and have complex roles in the different stages of $\mathrm{AD}$ pathophysiology (Carter et al., 2019). Astrocyte reactivity is an early feature of AD. Generally, reactive astrocytes can be divided into the following two categories: toxic reactive astrocyte, called "A1 astrocyte"; and protective reactive astrocyte, called "A2 astrocyte" (Liddelow et al., 2017). A recent single-nucleus RNA sequencing study reported that reactive astrocytes in the brain of $5 \times \mathrm{FAD}$ mice had a higher expression of inflammatory signatures (A1 astrocyte) than their control littermates; the study also reported that the astrocyte response appeared to be a switch in the phenotypic state during the process of $\mathrm{AD}$ pathology and normal aging (Habib et al., 2020). In the present study, greater numbers and larger areas of GFAP-positive astrocytes with enlarged soma were observed in the CA1 region and DG of vehicle-treated 6month-old male $5 \times \mathrm{FAD}$ mice than in their WT littermates; this finding indicates that astrocytes were reactive in $5 \times \mathrm{FAD}$ mice. In contrast, deletion of the Ephx2 gene significantly lowered the number of GFAP-positive cells. Moreover, the soma volume of GFAPpositive cells and the GFAP-covered area were smaller in 6-month-old $5 \times \mathrm{FAD}$;Eph $x 2^{-1-}$ mice than in their control littermates, indicating that the deletion of Ephx2 inhibited toxic astrocyte reaction. Interestingly, a recent study by Lee et al., showed that the deletion of Ephx2 diminished cerebral $\mathrm{A} \beta$ deposition, and improved the nesting ability as well as spatial learning and memory function in 6-month-old APP/PS1 Tg mice. However, the deletion of Ephx2 increased astrogliosis in the hippocampus of APP/PS1 Tg mice compared with that in control mice (Lee et al., 2019). Lee et al. also found that the expression levels of anti-inflammatory cytokines, such as interleukin (IL)-4 and IL-10, were high in the hippocampal astrocytes of APP/PS1 Tg/Eph $x 2^{-1-}$ mice compared with those of control mice. Moreover, they found that the deletion of Ephx2 significantly decreased the expression of BACE1 in the brains of APP/ PS1 Tg mice, which could contribute to diminished A $\beta$ deposition. These discrepancies could be attributable to the different animal models used. The major difference between the two model mice is that FAD mutations can be overexpressed in the astrocytes of APP/PS1 Tg mice, but not in the astrocytes of $5 \times \mathrm{FAD}$ mice; thus, this difference could lead to astrocytes adopting different reactive states. The $5 \times \mathrm{FAD}$ transgenic mouse model uses neuron-specific Thyl promoter to coexpress and overexpress APP with three FAD mutations, and presenilin 1 (PS1) with two FAD mutations (Oakley et al., 2006). In contrast, APP/PS1 Tg mice coexpress $\mathrm{Mo} / \mathrm{Hu}$ APPswe with a mutant PS1$\mathrm{dE9}$ gene under the control of the mouse prion protein promoter (Jankowsky et al., 2004). Together, these results indicate that EET signaling could modulate changes in astrocyte function in 
response to different pathologic conditions in $\mathrm{AD}$. Therefore, it will be interesting to perform new experiments to identify the underlying mechanism.

In summary, infusion of a higher concentration 14,15-EET $(200 \mathrm{ng} / \mathrm{ml})$ into the brain parenchyma eliminated $\mathrm{A} \beta$ deposits in whole-brain sections of 6 -month-old $5 \times$ FAD mice. Although the mechanistic basis for this effect is unclear, it can be addressed in future studies by microinjecting labeled 14,15-EET and observing its distribution in the brain. Nonetheless, this finding highlights the therapeutic potential of 14,15-EET for preventing or delaying the development and progression of $\mathrm{AD}$.

\section{References}

Butler AW, Ng MY, Hamshere ML, Forabosco P, Wroe R, Al-Chalabi A, Lewis CM, and Powell JF (2009) Meta-analysis of linkage studies for Alzheimer's disease-a web resource. Neurobiol Aging 30:10371047.

Cao X, Li LP, Qin XH, Li SJ, Zhang M, Wang Q, Hu HH, Fang YY, Gao YB, Li XW, Sun LR, Xiong WC, Gao TM, Zhu XH (2013a) Astrocytic adenosine 5'-triphosphate release regulates the proliferation of neural stem cells in the adult hippocampus. Stem Cells 31:1633-1643.

Cao X, Li LP, Wang Q, Wu Q, Hu HH, Zhang M, Fang YY, Zhang J, Li SJ, Xiong WC, Yan HC, Gao YB, Liu JH, Li XW, Sun LR, Zeng YN, Zhu XH, Gao TM (2013b) Astrocyte-derived ATP modulates depressive-like behaviors. Nat Med 19:773-777.

Carter SF, Herholz K, Rosa-Neto P, Pellerin L, Nordberg A, Zimmer ER (2019) Astrocyte Biomarkers in Alzheimer's Disease. Trends Mol Med 25:77-95.

Crivelli SM, Giovagnoni C, Visseren L, Scheithauer AL, de Wit N, den Hoedt S, Losen M, Mulder MT, Walter J, de Vries HE, Bieberich E, MartinezMartinez P (2020) Sphingolipids in Alzheimer's disease, how can we target them? Adv Drug Deliv Rev 20:30002-30008.

De Strooper B, Karran E (2016) The cellular phase of Alzheimer's disease. Cell 164:603-615.

Deczkowska A, Keren-Shaul H, Weiner A, Colonna M, Schwartz M, and Amit M (2018) Disease-Associated Microglia: A Universal Immune Sensor of Neurodegeneration. Cell 173:1073-1081.

DeMattos RB, Cirrito JR, Parsadanian M, May PC, O’Dell MA, Taylor JW, Harmony JA, Aronow BJ, Bales KR, Paul SM, Holtzman DM (2004) ApoE and clusterin cooperatively suppress Abeta levels and deposition: evidence that ApoE regulates extracellular Abeta metabolism in vivo Neuron 41:193-202.

Giralt A, de Pins B, Cifuentes-Díaz C, López-Molina L, Farah AT, Tible M, Deramecourt V, Arold ST, Ginés S, Hugon J, Girault J-A (2018) PTK2B/ Pyk2 overexpression improves a mouse model of Alzheimer's disease. Exp Neurol 307:62-73.

Habib N, McCabe C, Medina S, Varshavsky M, Kitsberg D, Dvir-Szternfeld R, Green G, Dionne D, Nguyen L, Marshall JL, Chen F, Zhang F, Kaplan T, Regev A, Schwartz M (2020) Disease-associated astrocytes in Alzheimer's disease and aging. Nat Neurosci 23:701-706.

Heneka MT, Kummer MP, Stutz A, Delekate A, Schwartz S, Vieira-Saecker A, Griep A, Axt D, Remus A, Tzeng T-C, Gelpi E, Halle A, Korte M, Latz E, Golenbock DT (2013) NLRP3 is activated in Alzheimer's disease and contributes to pathology in APP/PS1 mice. Nature 493:674-678.

Iaccarino HF, Singer AC, Martorell AJ, Rudenko A, Gao F, Gillingham TZ, Mathys H, Seo J, Kritskiy O, Abdurrob F, Adaikkan C, Canter RG, Rueda R, Brown EN, Boyden ES, Tsai LH (2016) Gamma frequency entrainment attenuates amyloid load and modifies microglia. Nature 540:230235.

Imig JD (2012) Epoxides and soluble epoxide hydrolase in cardiovascular physiology. Physiol Rev 92:101-130.

Jankowsky JL, Fadale DJ, Anderson J, Xu GM, Gonzales V, Jenkins NA, Copeland NG, Lee MK, Younkin LH, Wagner SL, Younkin SG, Borchelt DR (2004) Mutant presenilins specifically elevate the levels of the 42 residue beta-amyloid peptide in vivo: evidence for augmentation of a 42 -specific gamma secretase. Hum Mol Genet 13:159-170.

Karch CM, Goate AM (2015) Alzheimer's disease risk genes and mechanisms of disease pathogenesis. Biol Psychiatry 77:43-51.

Kawarabayashi T, Younkin LH, Saido TC, Shoji M, Ashe KH, Younkin SG (2001) Age-dependent changes in brain, CSF, and plasma amyloid $\beta$ protein in the $\mathrm{Tg} 2576$ transgenic mouse model of Alzheimer's disease. J Neurosci 21:372-381.

Kodani SD, Hammock BD (2015) The 2014 Bernard B. Brodie award lecture-epoxide hydrolases: drug metabolism to therapeutics for chronic pain. Drug Metab Dispos 43:788-802.

Koistinaho M, Lin S, Wu X, Esterman M, Koger D, Hanson J, Higgs R, Liu F, Malkani S, Bales KR, Paul SM (2004) Apolipoprotein E promotes astrocyte colocalization and degradation of deposited amyloid-beta peptides. Nat Med 10:719-726.

Lambert JC, Ibrahim-Verbaas CA, Harold D, Naj AC, Sims R, Bellenguez C, DeStafano AL, Bis JC, Beecham GW, Grenier-Boley B, Russo G, Thorton-Wells TA, Jones N, Smith AV, Chouraki V, Thomas C, Ikra MA, Zelenika D, Vardarajan BN, Kamatani Y (2013) Meta-analysis of 74,046 individuals identifies 11 new susceptibility loci for Alzheimer's disease. Nat Genet 45:1452-1458.

Lee HT, Lee KI, Chen CH, Lee TS (2019) Genetic deletion of soluble epoxide hydrolase delays the progression of Alzheimer's disease. J Neuroinflammation 16:267.

Liddelow SA, Guttenplan KA, Laura EC, Bennett FP, Bohlen CJ, Schirmer L, Bennett ML, Münch AE, Chung W-S, Peterson TC, Wilton DK, Frouin A, Napier BA, Panicker N, Kumar M, Buckwalter MS, Rowitch DH, Dawson VL, Dawson TM, Stevens B (2017) Neurotoxic reactive astrocytes are induced by activated microglia. Nature 541:481-487.

Liu Y, Wan Y, Fang Y, Yao E, Xu S, Ning Q, Zhang G, Wang W, Huang X, Xie M (2016) Epoxyeicosanoid signaling provides multi-target protective effects on neurovascular unit in rats after focal ischemia. J Mol Neurosci $58: 254-265$.

Martini-Stoica H, Cole AL, Swartzlander DB, Chen F, Wan YW, Bajaj L, Bader DA, Lee VMY, Trojanowski JQ, Liu Z, Sardiello M, Zheng H (2018) TFEB enhances astroglial uptake of extracellular tau species and reduces tau spreading. J Exp Med 215:2355-2377.

Matsubara E, Soto C, Governale S, Frangione B, Ghiso J (1996) Apolipoprotein J and Alzheimer's amyloid beta solubility. Biochem J 316:671-679.

McDade E, Bateman RJ (2017) Stop Alzheimer's before it starts. Nature 547:153-155.

Medina DL, Fraldi A, Bouche V, Annunziata F, Mansueto G, Spampanato C, Puri C, Pignata A, Martina JA, Sardiello M, Palmieri M, Polishchuk R, Puertollano R, Ballabio A (2011) Transcriptional activation of lysosomal exocytosis promotes cellular clearance. Dev Cell 21:421-430.

Minami SS, Min SW, Krabbe G, Wang C, Zhou Y, Asgarov R, Li Y, Martens LH, Elia LP, Ward ME, Mucke L, Farese RV Jr, Gan L (2014) Progranulin protects against amyloid $\beta$ deposition and toxicity in Alzheimer's disease mouse models. Nat Med 20:1157-1164.

Mizoguchi Y, Kato TA, Seki Y, Ohgidani M, Sagata N, Horikawa H, Yamauchi Y, Sato-Kasai M, Hayakawa K, Inoue R, Kanba S, Monji A (2014) Brain-derived neurotrophic factor (BDNF) induces sustained intracellular $\mathrm{Ca} 2+$ elevation through the up-regulation of surface transient receptor potential 3 (TRPC3) channels in rodent microglia. J Biol Chem 289:18549-18555.

Oakley H, Cole SL, Logan S, Maus E, Shao P, Craft J, Guillozet-Bongaarts A, Ohno M, Disterhoft J, Van Eldik L, Berry R, Vassar R (2006) Intraneuronal $\beta$-amyloid aggregates, neurodegeneration, and neuron loss in transgenic mice with five familial Alzheimer's disease mutations: potential factors in amyloid plaque formation. J Neurosci 26:10129-10140.

Polis B, Gil-Henn H (2019) Commentary on Giralt et al.: PTK2B/Pyk2 overexpression improves a mouse model of Alzheimer's disease. Exp Neurol 311:313-317.

Qin XH, Wu Z, Dong JH, Zeng YN, Xiong WC, Liu C, Wang MY, Zhu MZ, Chen WJ, Zhang Y, Huang QY, Zhu XH (2019) Liver soluble epoxide hydrolase regulates behavioral and cellular effects of chronic stress. Cell Rep 29:3223-3234

Reagh ZM, Noche JA, Tustison NJ, Delisle D, Murray EA, Yassa MA (2018) Functional Imbalance of Anterolateral Entorhinal Cortex and Hippocampal Dentate/CA3 Underlies Age-Related Object Pattern Separation Deficits. Neuron 97:1187-1198.

Sanchez-Mejia RO, Newman JW, Toh S, Yu GQ, Zhou Y, Halabisky B, Cissé M, Scearce-Levie K, Cheng IH, Gan L, Palop JJ, Bonventre JV, Mucke L (2008) Phospholipase A2 reduction ameliorates cognitive deficits in a mouse model of Alzheimer's disease. Nat Neurosci 11:1311-1318.

Sardiello M, Palmieri M, di Ronza A, Medina DL, Valenza M, Gennarino VA, Di Malta C, Donaudy F, Embrione V, Polishchuk RS, Banfi S, 
Parenti G, Cattaneo E, Ballabio A (2009) A gene network regulating lysosomal biogenesis and function. Science 325:473-477.

Schneider L (2020) A resurrection of aducanumab for Alzheimer's disease. Lancet Neurol 19:111-112.

Selkoe DJ (2019) Early network dysfunction in Alzheimer's disease. Science 365:540-541.

Settembre C, Di Malta C, Polito VA, Garcia Arencibia M, Vetrini F, Erdin S, Erdin SU, Huynh T, Medina D, Colella P, Sardiello M, Rubinsztein DC, Ballabio A (2011) TFEB links autophagy to lysosomal biogenesis. Science 332:1429-1433.

Shen D, Wang X, Li X, Zhang X, Yao Z, Dibble S, Dong XP, Yu T, Lieberman AP, Showalter HD, Xu H (2012) Lipid storage disorders block lysosomal trafficking by inhibiting a TRP channel and lysosomal calcium release. Nat Commun 3:731.

Tolar M, Abushakra S, Sabbagh M (2019) The path forward in Alzheimer's disease therapeutics: reevaluating the amyloid cascade hypothesis. Alzheimers Dement 1:1552-5260.

Wu CH, Shyue SK, Hung TH, Wen S, Lin CC, Chang CF, Chen SF (2017) Genetic deletion or pharmacological inhibition of soluble epoxide hydrolase reduces brain damage and attenuates neuroinflammation after intracerebral hemorrhage. J Neuroinflammation 14:230.

Wu Z, Guo Z, Gearing M, Chen G (2014) Tonic inhibition in dentate gyrus impairs long-term potentiation and memory in an Alzheimer's disease model. Nat Commun 5:4159.

Wyss-Coray T, Loike JD, Brionne TC, Lu E, Anankov R, Yan F, Silverstein SC, Husemann J (2003) Adult mouse astrocytes degrade amyloid-beta in vitro and in situ. Nat Med 9:453-457.
Xiao Q, Yan P, Ma X, Liu H, Perez R, Zhu A, Gonzales E, Burchett JM, Schuler DR, Cirrito JR, Diwan A, Lee JM (2014) Enhancing astrocytic lysosome biogenesis facilitates $\mathrm{A} \beta$ clearance and attenuates amyloid plaque pathogenesis. J Neurosci 34:9607-9620.

Xiong W, Cao X, Zeng Y, Qin X, Zhu M, Ren J, Wu Z, Huang Q, Zhang Y, Wang M, Chen L, Turecki G, Mechawar N, Chen W, Yi G, Zhu X (2019) Astrocytic epoxyeicosatrienoic acid signaling in the medial prefrontal cortex modulates depressive-like behaviors. J Neurosci 39:4606-4623.

Xu H, Ren D (2015) Lysosomal physiology. Annu Rev Physiol 77:57-80.

Yuan L, Liu J, Dong R, Zhu J, Tao C, Zheng R, Zhu S (2016) 15Epoxyeicosatrienoic acid promotes production of brain derived neurotrophic factor from astrocytes and exerts neuroprotective effects during ischaemic injury. Neuropathol Appl Neurobiol 42:607-620.

Zhang X, Cheng X, Yu L, Yang J, Calvo R, Patnaik S, Hu X, Gao Q, Yang M, Lawas M, Delling M, Marugan J, Ferrer M, Xu H (2016) MCOLN1 is a ROS sensor in lysosomes that regulates autophagy. Nat Commun 7:12109.

Zhang Y, Wang MY, Huang QY, Zhu MZ, Ren J, Cao X, Xiong WC, Xiao XD, Zhu XH (2018) An improved Ultra-High Performance Liquid chromatography-tandem mass spectrometry method for simultaneous quantitation of cytochrome P450 metabolites of arachidonic acid in human plasma. J Chromatogr A 1563:144-153.

Zhu XH, Yan HC, Zhang J, Qu HD, Qiu XS, Chen L, Li SJ, Cao X, Bean JC, Chen LH, Qin XH, Liu JH, Bai XC, Bai L, Gao TM (2010) Intermittent hypoxia promotes hippocampal neurogenesis and produces antidepressant-like effects in adult rats. J Neurosci 30:12653-12663. 